\title{
Epithelial ovarian cancer
}

A clinical epidemiological approach on diagnosis and treatment

\author{
Torbjørn Paulsen
}


(C) Torbjørn Paulsen, 2007

Series of dissertations submitted to the

Faculty of Medicine, University of Oslo

No.549

ISBN 978-82-8072-439-7

All rights reserved. No part of this publication may be

reproduced or transmitted, in any form or by any means, without permission.

Cover: Inger Sandved Anfinsen.

Printed in Norway: AiT e-dit AS, Oslo, 2007.

Produced in co-operation with Unipub AS.

The thesis is produced by Unipub AS merely in connection with the thesis defence. Kindly direct all inquiries regarding the thesis to the copyright holder or the unit which grants the doctorate.

Unipub AS is owned by

The University Foundation for Student Life (SiO) 
"It is the business if the physicians to know, in the first place, things similar and things dissimilar; those connected with things most important, most easily known, and in anywise known; which are to be seen, touched, and heard; which are to be perceived in the sight, and the touch, and the hearing, and the nose, and the tongue, and the understanding: which are to be known by all means we know other things."

\section{Hippocrates $^{1}$}

"Read not to contradict, nor to believe, but to weigh and consider"

Bacon $^{2}$ 


\section{TABLE OF CONTENTS}

$\begin{array}{ll}\text { Acknowledgements } & 6\end{array}$

$\begin{array}{ll}\text { Abbreviation } & 7\end{array}$

List of papers $\quad 8$

Aims 9

$\begin{array}{ll}\text { General introduction } & 10\end{array}$

$\begin{array}{ll}\text { Background } & 23\end{array}$

Materials and methods $\quad 24$

$\begin{array}{ll}\text { Summary of each paper } & 30\end{array}$

Discussion $\quad 33$

Implications $\quad 42$

Main conclusions $\quad 46$

$\begin{array}{ll}\text { Future perspectives and research } & 47\end{array}$

$\begin{array}{ll}\text { References } & 50\end{array}$

Papers $1-4$

Appendix

12.1 Instructions to the clinical form

12.2 Clinical form to the Cancer Registry of Norway

12.3 Questionnaire to gynaecological units in Norway, 2000

12.4 Validity of dataelements

12.5 Proposed surgical record form 


\section{ACKNOWLEDGEMENTS}

A special thanks to Frøydis Langmark, Director of the Cancer Registry of Norway, for making this project possible. She helped me with financial and moral support.

Without the great effort of my tutors Janne Kærn, Kristina Kjærheim and Claes Tropé in guiding me through the planning and writing process, this thesis would never have been accomplished. Steinar Tretli and Tor Haldorsen gave me important statistical insight. Jahn Nesland made it possible for me to analyse the immunhistochemistry data and Anne Hansen Ree gave valuable support in writing the last paper. Assia Bassarova was of great help in running positive and negative controls and supplying the last paper with outstanding photographs. Aasmund Berner checked the interobserver compliance.

Svein Erling Tysvær programmed a database in Firebird on the basis of the clinical form. This program was an important tool in the data collection.

I thank Mette Bergmann, Grete Kjølberg, encoders of the Cancer Registry for the outstanding work in encoding clinical data into the OVANOR database, Bjarte Aagnes for the compilation of the graphics, and SPSS support, and Bjørge Sæther for creating the incidence plots.

Ingunn Herredsvela and Jarle Norstein helped me in developing the clinical form.

Further, I am thankful to Ellen Hellesylt, Mette S. Ingrud, and Anne-Marie Becker from the department of pathology, DNR for preparation and immunological staining of antibodies. A special thanks to the clinicians who filled in the registration forms, and the persons who sent pathological, medical, and surgical records to the Cancer Registry. Without help from all these people, the present thesis would not have been accomplished.

I will give a special thank to Mr. John Fredriksen and Ms. Inger Fredriksen Foundation for financial support to paper 4.

Foremost, a special thanks to my wife Siri for her insightsful comments along the path toward this thesis. Last but not least, without the support and understanding of my children Synøve, Solveig and Astrid, this thesis would not have been realized. 


\section{ABBREVIATIONS}

BRAF

v-raf murine sarcoma viral oncogene homolog B1. Chromosome: $7 \mathrm{q} 34$

CEA Carcinoembryonic antigen

CT Computer tomography

EOC Eithelial ovarian cancer

FIGO International Federation of Gynaecology and Obstetrics

GYN Gynaecological

HLA-G HLA-G histocompatibility antigen, class I,G. Chromosome: 6q213

HR Hazard ratio

HS Haematoxylin staining

ICD-10 International Classification of Disease - Version 10

KRAS V-Ki-ras2 Kristen rat sarcoma viral oncogne. Chromosome: $12 \mathrm{p} 12.1$

MMP Matrix metallinoproteases

MRI Magnetic resonance imaging

NTH Non-teaching hospitals

OR Odds ratio

OVANOR Population-based clinical register of ovarian cancer in Norway, established in 2002

TH Teaching hospitals

TP53 tumour protein p53 gene

RMI Risk of malignancy index

S-BOT Serous borderline ovarian tumours (= SBT)

SCI Surgery chemotherapy interval

TIMP Tissue inhibitors of metalloproteases

VEGF Vessel endothelial growth factor

VEGFR Vessel endothelial growth factor reseptor

WHO World Health Organization 


\section{LIST OF PAPERS}

1. Paulsen T, Kærn J, Kjærheim K, Tropé C, Tretli S. Symptoms and referral of women with epithelial ovarian tumors. Int J Gynaecol Obstet 2005 88: 31-37

2. Paulsen T, Kjærheim K, Kærn J, Tretli S, Tropé C. Improved short-term survival for advanced ovarian, tubal and peritoneal cancer patients operated at teaching hospitals. Int J Gynecol Cancer 200616 (Suppl. 1): 11-17

3. Paulsen T, Kærn J, Kjærheim K, Haldorsen T, Tropé C. Influence on short-term survival of interval between primary surgery and chemotherapy in advanced ovarian, tubal and peritoneal cancer patients. Gynecol Oncol 2006102 (3): 447452. Epub 2006 March 3

4. Paulsen T, Ree AH, Kærn J, Kjærheim K, Bassarova A, Berner A, Haldorsen T, Tropé C, Nesland JM. Expression of matrix metalloproteinase-2 in serous borderline ovarian tumors is associated with noninvasive implant formation. Eur $J$ Gynaecol Oncol 2007 XXVIII, 5: 356-363 


\begin{abstract}
AIMS
The main aim was to reveal shortcomings in diagnosis and treatment for epithelial ovarian cancer (EOC) patients in order to improve diagnostic procedures and therapy together with increased biological knowledge. A systematic registration of all ovarian cancer patients on a national level was performed with a focus on symptoms, diagnosis, surgery, and chemotherapy.
\end{abstract}

\title{
Paper 1
}

We hypothesized that a large proportion of epithelial ovarian cancer patients were referred to non-gynaecological (GYN) units in Norway. The aim was to investigate how symptoms influenced referral of patients to different hospital units.

\section{Paper 2}

We hypothesized that advanced EOC patients treated at teaching hospitals (TH) had improved survival compared to those treated at non-teaching hospitals (NTH). The aim was to evaluate the impact on survival of hospital level and operating physician's speciality.

\section{Paper 3}

In animal models, short surgery chemotherapy interval (SCI) improve survival, therefore we hypothesized that advanced EOC patients with short SCI had improved survival. The aim was to demonstrate the possible survival impact of SCI for EOC patients.

\section{Paper 4}

In EOC, high levels of MMP and VEGF are associated with metastic spread of disease $^{3 ; 4}$. We considered that non-invasive implant formation in borderline ovarian tumors (BOT) followed the same principle as metastasis formation in EOC. The aims were to illuminate the biological mechanisms of non-invasive implant formation and to investigate the prognostic effect from the presence of non-invasive implants on diseasefree survival. 


\section{GENERAL INTRODUCTION}

\section{Symptoms}

Two thirds of EOC patients are diagnosed primarily with advanced disease, probably because symptoms are vague and nonspecific in early stages. The patient may be asymptomatic when an abdominal mass is discovered during routine pelvic examination. This is often the case for patients with BOT. Abdominal pain, distended abdomen, bowel irregularity, and persisting fatigue are frequent symptoms in advanced EOC patients. The sensation of an abdominal mass is shown to be more common in women with ovarian cancer than other pelvic cancers ${ }^{5}$. Abdominal pain is often caused by pressure of the tumour against abdominal organs. Distended abdomen, ascites and subileus may also cause abdominal pain. Infiltrative growth in the intestines may cause bowel irregularities as constipation, small stool diameter, ileus or rectal bleeding. Some patients experience vaginal bleeding or discharge, urinary urgency, and respiratory difficulties. The latter symptom may be caused by distended abdomen with pressure against the diaphragm, and pleural efusion. Acute symptoms, as pain due to rupture or torsion, are infrequent ${ }^{6 ; 7}$. Some women with EOC may falsely be diagnosed as gastritis, irritable bowel syndrome, stress or depression ${ }^{8}$. In paper 1, we described the symptoms of EOC and BOT patients.

\section{Incidence and prevalence of ovarian cancers}

The age-standardised incidence rate for EOC has not changed much during the last decades. The incidence of EOC was 9.3 per 100000 women-years in 1957 and 11.6 in 2004 in Norway (Figure 1) ${ }^{9}$. The rates in the Scandinavian countries are among the highest in the world. World wide there are 204000 new cases of ovarian cancer diagnosed annually with an estimated 125000 disease related deaths ${ }^{10}$. The incidence rate of BOT was 5.0 per 100000 women-years in $2004^{9}$. The prevalence ${ }^{\mathrm{a}}$ of EOC and non-EOC patients in Norway was 3521 in 1994 and 4104 in 2004. For BOT the prevalence were 1287 in 1994 and 2283 in 2004. The majority of EOC patients are not cured, while most BOT patients are cured. In the general population the lifetime risk for developing EOC is $1.4 \%{ }^{11}$.

There was a fall in incidence of EOC from 12.8 per 100000 women-years in 2002 to 10.5 in 2003, which might be explained by a variation by chance. In 2004 the incidence was 11.6 thus no trend was seen.

\footnotetext{
${ }^{\mathrm{a}}$ Patients cured and living with disease
} 
The World Health Organization's (WHO) introduction of a more precise pathological definition of $\mathrm{BOT}^{12}$ has probably lead to an increasing incidence of BOT (Figure1).

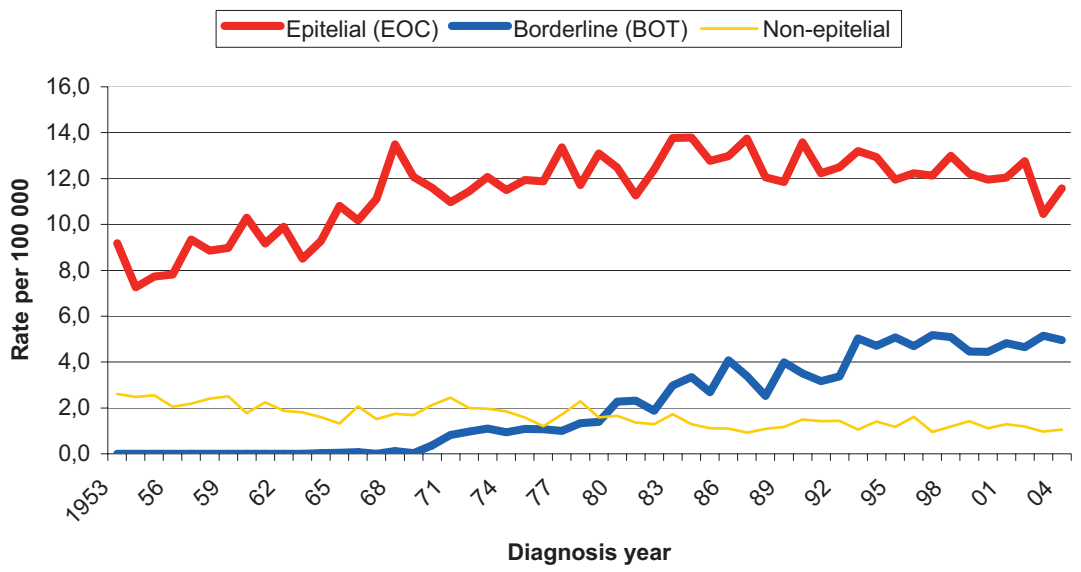

Figure 1. Age-adjusted incidence rates for all stages 1953 to 2004 for patients with epithelial ovarian cancer (EOC), non-EOC and borderline ovarian tumors (BOT) in Norway. Data from Cancer Registry

\section{Mortality and survival}

EOC is the female genital cancer with the highest mortality in the western world ${ }^{13}$. The five-years relative survival for patients with EOC in Norway has improved over time, but is still only $42 \%$ for all stages (1995 - 1999; personal communication: Bjørge Sæther, Cancer Registry). In the time period 1995 - 1999 five-years survival for patients with localized disease EOC is $90 \%$. BOT has much better survival, both in localized and advanced stages. Five-years survival is $99 \%$ in stage $\mathrm{I}^{14}, 98 \%$ in S-BOT with noninvasive implants and $33 \%$ in those patients with invasive implants ${ }^{15}$. 


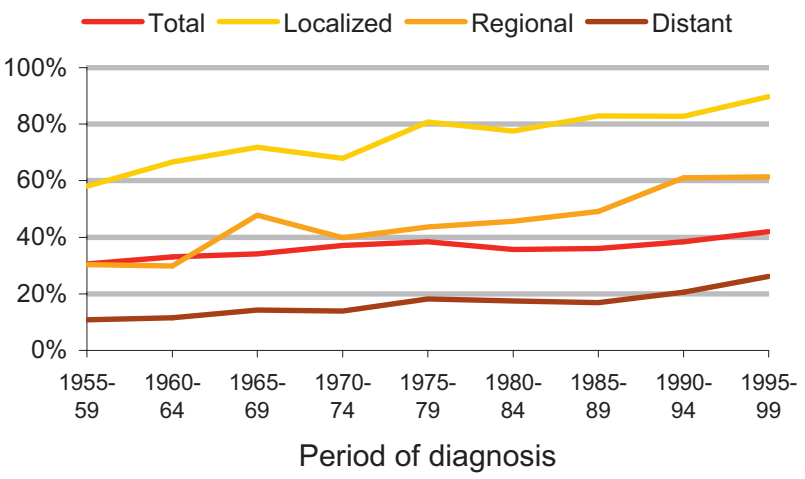

Figure 2. Five-years relative survival by stage for epithelial ovarian cancer (EOC), diagnosed in the period 1955 - 1999. Data from Cancer Registry

Histology (Table 1)

Epithelial ovarian cancers (EOC)

These tumours constitute more than $90 \%$ of all ovarian tumours ${ }^{16}$.

EOC are classified as serous (63\%), endometroid (12\%), mucinous (9\%), clear cell (7\%) while other types (9\%) comprise the rest of the tumours (Paper 1).

Borderline ovarian tumours (BOT)

BOT consist of the epithelial subgroups: serous (56 \%), mucinous (42\%), endometroid ( $2 \%)$, and others $(<1 \%$ ) (Paper 1$)$. According to WHO's classification ${ }^{17}, \mathrm{~S}-$ BOT consist of the typical $(90 \%)$ and the micropapillary type $(5-10 \%)$. Some tumours might be associated with peritoneal implants of either non-invasive or invasive type. SBOT might develop into low grade serous carcinoma via the "low-grade" pathway ${ }^{18 ; 19}$ (Figure 3).

Non-epithelial ovarian cancer patients were excluded from the analyses in the present thesis because these cancers have a different genetic origin and are treated with less extended surgery and other chemotherapeutic regimens than EOC patients. The survival pattern is also different ${ }^{20}$. 
Table 1. WHO's histological classification of ovarian cancers $^{17}$

\begin{tabular}{|c|c|c|c|}
\hline Main type & Subtype & $\begin{array}{l}\text { Included } \\
\text { in the } \\
\text { thesis }\end{array}$ & $\begin{array}{l}\text { Included in } \\
\text { OVANOR } \\
\text { registry }\end{array}$ \\
\hline \multicolumn{4}{|l|}{ Epithelial } \\
\hline $\begin{array}{l}\text { EOC (including tubal } \\
\text { and peritoneal cancer) }\end{array}$ & $\begin{array}{l}\text { Serous, mucinous, endometroid, } \\
\text { clear cell, transitional, squamous, } \\
\text { mixed epithelial tumours, } \\
\text { undifferentiated }\end{array}$ & yes & yes \\
\hline BOT & $\begin{array}{l}\text { Serous, mucinous, endometroid, } \\
\text { clear cell, transitional, squamous, } \\
\text { mixed epithelial tumours }\end{array}$ & yes & yes \\
\hline \multicolumn{4}{|l|}{ Non-epithelial } \\
\hline & $\begin{array}{l}\text { Sexcord stromal, germ cell, } \\
\text { tumours of the rete ovarii, } \\
\text { miscellaneous tumours, tumour } \\
\text { like conditions, lymphoid and } \\
\text { haematopoetic tumours, secondary } \\
\text { tumours }\end{array}$ & no & yes \\
\hline
\end{tabular}

Epithelial ovarian cancer is defined as epithelial ovarian cancer (EOC) and borderline ovarian tumours (BOT)

Ovarian cancer is defined as epithelial and non-epithelial ovarian cancers

\section{Etiology and risk factors}

Although the causes of EOC remain uncertain, hypotheses relating to incessant ovulation $^{21}$, excessive gonadotropin secretion, retrograde (asbestos and talc) carcinogen transportation $^{22 ; 23}$ and estrogen/progestin imbalance have been suggested as etiological explanations for developing EOC. The epidemiological evidence for these hypotheses is not consistent. Some evidence supports estrogen, although stronger evidence implicates factors related to androgens and progesterone as ethiological factors ${ }^{24}$. Familial history make up approximately $10 \%$ of the causes while the rest spontaneously occurring ${ }^{25}$. Polycystic ovarian syndrome, pelvic inflammatory disease, obesity, endometriosis, and hormonal replacement therapy during menopause have been shown to increase the risk of $\mathrm{EOC}^{26-28}$. Data on obesity is conflicting. Some authors have demonstrated an increased risk of EOC with increasing body mass index $^{27}$, while others have shown a lower risk. However, obese women had a higher frequency of $\mathrm{BOT}^{28}$.

Multiple births, breastfeeding and contraceptive pills appear to protect against EOC. Tobacco smoking may reduce the risk ${ }^{29}$. The use of nonsteroid anti-inflammatory drugs 
have also been discussed as protectors ${ }^{30}$. Surgical ligation of the phallopian tubes and hysterectomy may also reduce the risk ${ }^{26}$. Epidemiological data on the association with physical activity and EOC is however conflicting ${ }^{31 ; 32}$.

\section{Prognostic variables}

Many prognostic variables have been described for EOC. The most important variables used in the clinical setting are: residual disease, FIGO stage, ascites, grade of differentiation, histologic type, age, performance status $(\mathrm{WHO})^{33}, \mathrm{CA}-125$ levels at diagnosis and post-surgery, and DNA ploidy ${ }^{34}$. These prognostic variables are examined in the papers making up this thesis.

\section{Possible prognostic variables}

Many studies have been published that characterize tumours based on over- or under- expression of a multitude of genes (TP53, HER2, Bcl-2, Ki-67, PDGFRa, MMP2, P-glycoprotein, VEGF-C, VEGFR-2, MVD, AP-2 $\gamma$, MAP2K4 gene, MAD1L gene, and serine proteinase genes ${ }^{35-39}$ ). Researchers have identified malignant phenotypes based on gene expression profiles, distinguished BRCA-1 and BRCA-2 from germline tumours, and classified borderline tumours based on protein expression ${ }^{40 ; 41}$. Some studies have been performed on EOC using microarrays ${ }^{42 ; 43}$. These studies are promising with regard to predicting optimal surgery and chemotherapy resistance ${ }^{43}$.

\section{Pathogenesis}

Cancer is an acuired genetic disease in which a single clone of cells and its progeny accumulate heritable changes that results in the cellular phenotype of cancer ${ }^{44}$. The cells evolve progressively from normality via a series of premalignant states into invasive cancers ${ }^{45}$. Cancer cells have defects in regulatory circuits that govern normal cell proliferation and homeostasis ${ }^{46}$. Hanahan and Weinberg proposed six essential alterations in cell physiology that collectively dictate malignant growth: self-sufficiency in growth signals, insensitivity to growth-inhibitory signals, evasion of programmed cell death (apoptosis), limitless replicative potential, sustained angiogenesis, tissue invasion and metastasis ${ }^{46}$.

Genetic mutations that involve DNA repair such as BRCA, MSH-2, MLH-2, PMS 1 and PMS 2 gene mutations appear to increase the risk of $\mathrm{EOC}^{47}$.

Recently a new theory has been developed, describing a subset of serous ovarian cystadenomas that evolve through S-BOT to low-grade EOC"19 (Figure 3). This "lowgrade" pathway involves mutations in the BRAF/KRAS signalling pathway. The pathway involves S-BOT as a precursor mimicking the adenocarcinoma sequence in colorectal 
cancer in which carcinoma evolves through a continuum of histological precursor lesions. Only $2 \%$ of all S-BOT progress to carcinoma via the "low-grade" pathway ${ }^{48}$. Earlier it has been proposed that EOC did not have a premalignant phase like many other cancers (breast, cervical, colorectal), but developed rapidly from inclusion cysts into an invasive and widespread stage $\mathrm{e}^{49 ; 50}$. This "high-grade" pathway was also included in the new theory by Shih and Kurman ${ }^{18 ; 19}$. The latter pathway involved frequent TP53 mutations and very seldom BRAF/KRAS mutations. No precursor has until now been identified in the "highgrade" pathway. EOC probably develops via either of these two pathways. In paper 4 we disussed some aspects of the "low-grade" pathway.

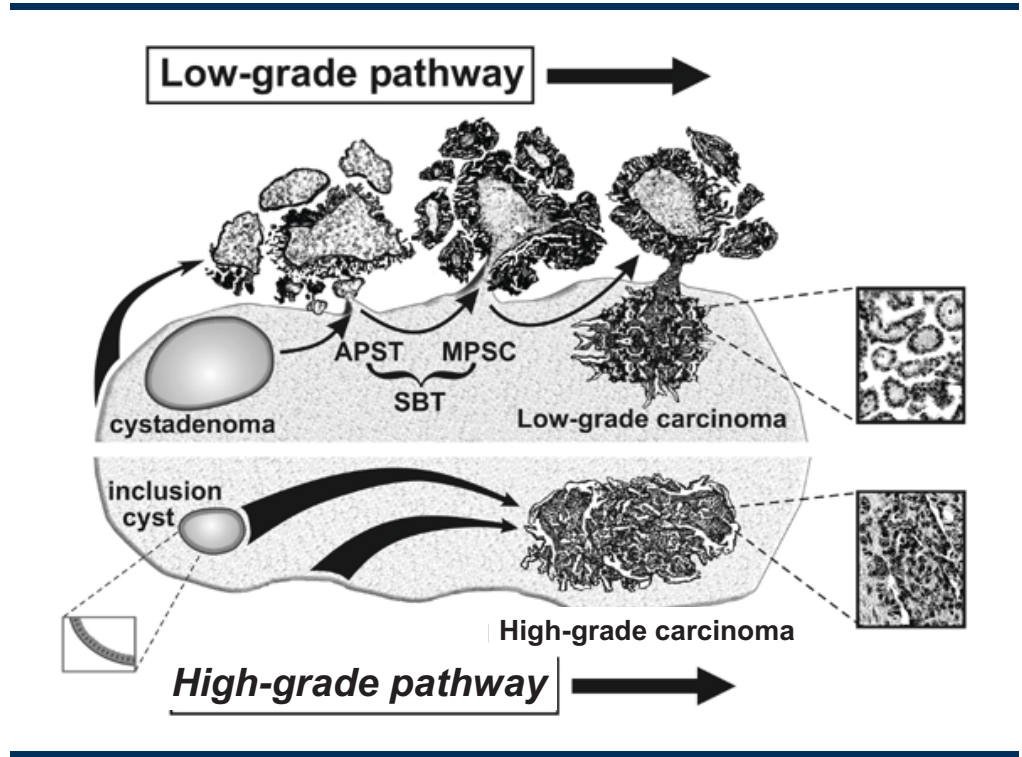

Figure 3. "Low-grade" pathway: frequent BRAF/KRAS mutations (61 - $68 \%$ ), low cellular proliferation, gradual increase in chromosomal instability, five-year survival $\approx 55 \%$; "High-grade" pathway: frequent TP53 mutations (70\%), high cellular proliferation, high chromosomal instability, frequent HLA-G expression, five-years survival $\approx 30 \%$. APST: Atypical proliferative serous tumours, $S B T=S-B O T=$ Serous borderline ovarian tumours, MPSC: Micropapillary serous carcinoma ${ }^{18}$. The figure was presented in a lecture by R. J. Kurman on Crete, June 2006. With permission

\section{Tissue invasion and metastasis}

Matrix metallinoproteases (MMP) and vessel endothelial growth factors (VEGF) play an important role in cell physiology leading to tissue invasion and metastasis. In 1962 Gross and Lapière first described the MMP in metamorphosis in frogs ${ }^{51}$. Growth factors and oncogenes induce the expression of genes expressing extracellular matrix-degrading proteins. These enzymes are capable of degrading basement membrane and connective 
tissue proteins. Recently, it has become clear that these enzymes contribute to many stages in tumour progression, including growth, angiogenesis, and development of early stage tumours. In addition, their substrates are much broader than matrix components alone, and include growth factors, together with their receptors, chemokines, apoptotic factors, and adhesion molecules. The MMP are required in many biological processes such as embryogenic development, organ morphogenesis, angiogenesis, cartilage remodeling, bone growth and wound healing ${ }^{52 ; 53}$.

One of the major structural components of the basement membrane, the type IV collagen, is substrate for MMP- $2^{54}$ and is highly degraded during tumour cell invasion. Like most metallinoproteases, MMP-2 is secreted as a proenzyme, which is processed extracellularly to generate an active gelatinase ${ }^{55 ; 56}$. This activation process has a complex mechanism $^{57}$ involving a membrane-bound MMP termed membrane-type 1 (MT1) MMP, or MMP-14. A specific MMP-2 inhibitor, the type 2 tissue inhibitor of MMP (TIMP-2) ${ }^{58}$, probably exercises its inhibitory function near the MMP-14 binding sites. The mechanism of MMP-2 activation also involves TIMP-2 bound to the MMP-2 and MMP-14 ${ }^{59}$. The matrix degrading enzymes might contribute to the development of a variety of pathological conditions by misregulation. In paper 4 the MMP and VEGF were used to illuminate the biological mechanisms in non-invasive implant (metastasis) development in S-BOT.

\section{Hospital level}

In Norway, EOC and BOT patients are treated at three hospital levels; local hospitals $(n=40)$, central hospitals $(n=12)$, and regional hospitals (one hospital in each of the four Health Regions). Only the regional hospitals include gynaecological oncology units and medical schools. The regional hospitals were defined as teaching hospitals (TH) and the others as non-teaching hospitals (NTH). Paper 2 address, differences in patient outcome between these two hospital levels.

\section{Staging}

The majority of EOC patients have widespread tumour dissemination in the abdominal cavity at time of diagnosis. During the period 1992 - 1997 in the United States, $58 \%$ of women with ovarian cancer had distant spread. Thirteen percent had regional spread, $20 \%$ localized, and $9 \%$ were unstaged (based on 53711 cases) ${ }^{60}$. In gynaecological departments the FIGO staging system is used (Appendix 12.1) ${ }^{61}$. The system is based on a detailed description of tumour spread inside and outside the abdominal cavity at primary surgery. The maximum tumour diameter is registrated in centimetres. Tumour spread outside the abdominal cavity must be verified by biopsy or 
cytology. Stage migration is defined as microscopic spread (verified by biopsy) outside the ovaries (omentum, peritoneum, lymph nodes, or other organs) in suspected lower stage disease. The performace of a more exact staging procedure will lead to stage migration. In paper 1 we showed the distribution of FIGO stages in EOC and BOT patients (Figure 4).

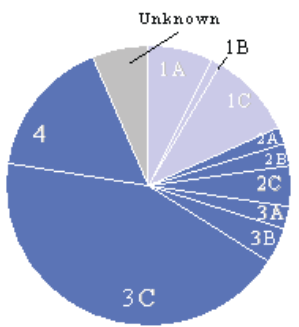

A

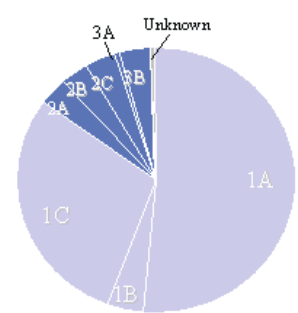

B

Figure 4. Primary epithelial ovarian cancers in Norway according to FIGO stage (Appendix 12.1) ${ }^{61}$, diagnosed 2002.

A. Epithelial ovarian cancers (EOC) $(n=486): 1 A(8 \%), 1 B(1 \%), 1 C(10 \%), 2 A(2 \%)$, $2 B(3 \%), 2 C(5 \%), 3 A(3 \%), 3 B(4 \%), 3 C(43 \%), 4(16 \%)$, unstaged $(6 \%)$.

B. Borderline ovarian tumours (BOT) $(n=137)$ : $1 A(52 \%), 1 B(4 \%), 1 C(31 \%), 2 A(4$ $\%), 2 B(4 \%), 2 C(4 \%), 3 A(1 \%), 3 B(4 \%), 3 C(0 \%)$, unstaged (1\%). Data from OVANOR registry

\section{Treatment}

\section{Surgery}

EOC patients in stages I and II are treated with peritoneal cytology, random peritoneal biopsies, total abdominal hysterectomy, bilateral salpingoopherectomy, omentectomy, pelvic/paraaortic lymphadenectomy ${ }^{62}$, and appendectomy in selected cases (mucinous tumours). Lymphadenectomy is performed in order to rule out tumour spread outside the ovaries ${ }^{63}$. BOT patients in stages I to III are treated with peritoneal cytology, random peritoneal biopsies, total abdominal hysterectomy, bilateral salpingoopherectomy, omentectomy, pelvic/paraaortic lymp node sampling, and appendectomy in selected cases (mucinous tumours). 
Young women with EOC and BOT with non-clear cell tumours in stage IA, grade 1, diploid, and normal CA-125 level ( $<35 \mathrm{kU} /$ liter) preoperativly might be managed conservatively with preservation of their reproductive potential ${ }^{64}$. Only retrospective studies support this treatment modality. The operating physcican must discuss the option of preserving fertility with the patient before surgery.

The recomended operation on women with advanced EOC includes total abdominal hysterectomy, bilateral salpingoophorectomy, complete omentectomy, resection of any tumour lesions on the peritoneal surface in the abdominal cavity (liver, spleen, diaphragm), pelvic, and paraaortic lymph node sampling or lymphadenectomy ${ }^{16}$. In cases of tumour spread to the bowel where optimal cytoreduction can be accomplished removal of the bowel is recommended. The principle of maximum cytoreductive surgery for advanced EOC was first described in the thirties by Meigs ${ }^{65}$ and later supported by a study of Aure et al. ${ }^{66}$. Among 102 patients Griffiths et al. ${ }^{67}$ demonstrated that a reduction of residual disease to less than $1.6 \mathrm{~cm}$ irrespective of the number of remaining tumours resulted in improved survival. Other studies have confirmed these findings ${ }^{68-72}$. Bristow et al. fitted a regression model to 81 patient cohorts a total of 8865 patients, showing that a $10 \%$ increase in maximal cytoreduction was associated with $5.5 \%$ increase in median survival time ${ }^{73}$. In recent years, surgical techniques have been developed in order to achieve maximal tumour reduction $^{74-78}$. The benefit of performing extensive surgery in the upper abdomen for women with widespread disease is still debated ${ }^{79 ; 80}$.

Many authors have questioned whether the resectability of a tumour is a reflection of biology or surgical skill ${ }^{79 ; 81-83}$. These authors claim that optimal surgery is dependent on tumour biology. Crawford et al. found that patients in stage IC - IIC EOC that were optimally debulked had a survival benefit compared to patients in stage III - IV EOC also being optimal debulked ${ }^{79}$. This study had limited information on substages. The authors concluded that a selection of patients to aggressive debulking should be done in patients with preoperatively less extensive disease. This is in contrast to the findings of Eisenkop et al., which demonstrated that cytoreduction to no residual disease has a more significant influence on survival regardless of disease extention before surgery ${ }^{84}$. Only patients in stage IIIC were included in this study. However, there was no information on residual tumour volume, which is an important prognostic factor. These differences in methodology might explain the different outcome among these studies.

In a recently published paper from the United States, the hospital and the surgeons' operating volume were not associated with improved survival ${ }^{85}$. A lack of accurancy in 
registration might be one explanation why operating volume was not associated with better outcome. Other authors have shown that surgery by a consultant gynaecological oncologists improved the outcome for EOC patients ${ }^{10 ; 72 ; 86-91}$.

Several authors have shown that treatment at a higher hospital level was associated with better prognosis ${ }^{92-95}$. In a retrospective Finish study the patients had more extensively surgery at $\mathrm{TH}$ and better outcome compared to $\mathrm{NTH}^{92}$. In paper 2 we used a prospective design to examine the hospital level and surgeon specialty effect on patients' survival.

\section{Chemotherapy}

The introduction of postoperative chemotherapy in advanced EOC treatment was not based on results from randomized trials. Studies have indicated that survival of patients with advanced EOC given postoperative chemotherapy is better than for patients not given chemotherapy ${ }^{96-103}$. The results from prospective, randomized trials on advanced EOC have shown that combination treatment with carboplatin and paclitaxel is more effective than other regimens ${ }^{104-106}$. During the time period $1984-2001$ a study from the Norwegian Radium Hospital demonstrated improved survival for EOC patients in the last five-years period. This improvement in survival was partly achieved by addition of paclitaxel ${ }^{107}$ (Figure 5). 


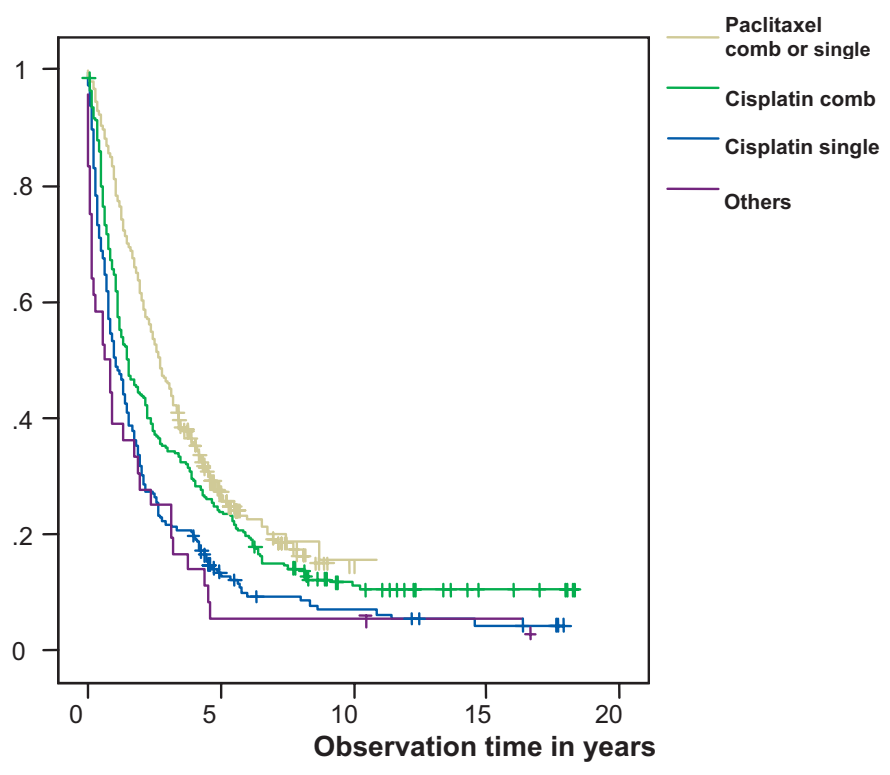

Figure 5. Overall Kaplan-Meier survival curves by different chemotherapy regimens for epithelial ovarian cancers (EOC) patients FIGO IIIC, diagnosed in the period 1985 - 2000 at the Norwegian Radium Hospital, $P<0.001^{107}$

The current standard treatment for advanced EOC in the western world is primary maximal cytoreductive surgery followed by six cycles of carboplatin and paclitaxel every three weeks. The patients are followed with pelvic examination, CT scan (if measurable lesions), and CA-125 after 3 and 6 cycles. It is still debated whether the interval between surgery and first chemotherapy cycle has a prognostic role. In animal models short time interval between surgery and chemotherapy (SCI) improve survival ${ }^{108 ; 109}$. This has not been supported by retrospective clinical studies ${ }^{110 ; 111}$. In paper 3 , we addressed this question by a prospective, population-based study.

The primary route of spread throughout the peritoneal cavity opens the possibility for therapy directed towards the peritoneal cavity. For many years clinicians have debated the role of intraperitoneal chemotherapy administration ${ }^{112-114}$. Armstrong et al. demonstrated that patients who received part of their chemotherapy by the intraperitoneal route had a median survival of 16 months longer compared to women who received intravenous chemotherapy only (65.6 versus 49.7 months) ${ }^{112}$. Present data indicate that cisplatin given intraperitoneally has a higher concentration in tumour cells compared to carboplatin $^{112}$. Many research centres claim that intraperitoneal chemotherapy should be 
offered as an option for optimally debulked EOC patients within randomized clinical trials. Intraperitoneal chemotherapy may be combined with hyperthermia, which enhances tissue penetration and cytotoxic activity of many drugs ${ }^{115-118}$. The role of hyperthermia in treatment of EOC is still not established. The current evidence for colorectal carcinoma with peritoneal carcinomatosis suggests that cytoreductive surgery combined with perioperative intraperitoneal chemotherapy is associated with improved survival compared with systemic chemotherapy ${ }^{119}$. This may also be the case for EOC. However, the patients receiving intaperitoneal chemotherapy had more serve toxicity (grade $3-4$, fatigue, hematologic, gastrointestinal, metabolic, and neurologic). Only $42 \%$ of the patients in the intraperitoneal group completed six cycles compared to $83 \%$ in the intravenous group ${ }^{112}$. Few patients completed the intraperitoneally treatment, thus there was a selection of patients to this treatment. The intravenous route is still the recommended administration route of chemotherapy for patients outside clinical trials.

In a large prospective, randomized European study ${ }^{120}$ the role of neoadjuvant chemotherapy in advanced EOC in reducing tumour volume before surgery has been addressed. The study was closed in 2006 after recruitment of the estimated number of patients. Retrospective studies, however, have shown benefit for neoadjuvant chemotherapy $^{121 ; 122}$, while a prospective study from the United States did not ${ }^{123}$.

New therapies

In frontline therapy trials, two design strategies are employed. 1) The novel agent may be administrated concurrently with standard chemotherapy showing promising results for some drugs ${ }^{124}$. 2) Alternatively, the agent may be given following the standard treatment as maintenance therapy ${ }^{125}$.

Clinical trials so far have shown little effect of chemotherapy in combination with small molecule inhibitors of metalloproteinases ${ }^{126 ; 127}$. One of the most promising supplementary agents is the angiogenetic inhibitor, Bevacizumab. Several clinical studies in first-line treatment for recurrent EOC ${ }^{128-130}$ and in other cancers ${ }^{131 ; 132}$ have been carried out using Bevacizumab. Two prospective, randomized trials (GOG study 218 and ICON7) are ongoing, treating the patients upfront with standard chemotherapy carboplatin (C) and paclitaxel (T) and in the experimental arm addition of Bevacizumab (B) or placebo (P). The addition of Bevacizumab is also given as maintenance therapy in one study arm and placebo in the two other arms $(\mathrm{C}+\mathrm{T}+\mathrm{P} \rightarrow \mathrm{P} ; \mathrm{C}+\mathrm{T}+\mathrm{B} \rightarrow \mathrm{P} ; \mathrm{C}+\mathrm{T}+\mathrm{B} \rightarrow \mathrm{B})$.

There is some evidence to suggest that adjuvant radiotherapy after radical surgery leads to increased disease-free survival for patients with advanced EOC. Intra abdominal 
fibrosis after total abdominal radiotherapy does not seem to be a considerable problem ${ }^{133}$, though many patients develop acute toxicity including diarrhea and abdominal pain. A considerable portion of patients develop chronic toxicity as fistulas, malabsorption, diarrhea, bowel adhesions and bladder problems ${ }^{134}$. It is known from other studies that second malignancies might develop in the irradiated area after many years ${ }^{135 ; 136}$.

\section{Response evaluation}

In 2000 the response evaluation criteria in solid tumours (RECIST) was published ${ }^{137}$. At the moment CT scan is the most reproducible methods for measuring target lesions selected for response assessment in ovarian cancer. Patients participating in randomized trials should have defined target lesions up to a maximum of five lesions per organ and 10 lesions in total. Target lesions should be selected on the basis of their size (those with the longest diameter). For practical reasons, only the largest target lesion is selected for patients outside randomized trials.

The evaluation of response according of the WHO criteria: complete response - the disappearance of all target lesions and no new lesions; partial response - at least a $30 \%$ decrease in the sum of the longest diameter of target lesions; progressive disease - at least a $20 \%$ increase in the sum of the longest diameter of target lesions; stable disease - neither sufficient shrinkage to qualify for partial response nor sufficient increase to qualify for progressive disease.

In patients without visible target lesions on CT scan and patients outside of randomized trials other response criteria might be used: pelvic examination, vaginal ultrasound, serum CA-125 and chest X-ray. 


\section{BACKGROUND}

The development of ovarian cancer surgery from the first described removal of an ovarian tumour in $1809^{138}$ until today has been accompanied with large improvements in operating techniques ${ }^{74-76 ; 139-141}$, and health care organization 90;93;142. Introduction of chemotherapy ${ }^{143}$ was another major advantage in EOC treatment that has lead to improved survival $^{96 ; 100 ; 102 ; 103 ; 107}$ (Figure 5). Despite these improvements, long-term survival for EOC patients is still inferior to many other cancer patients ${ }^{9}$. EOC has often been described as the "silent killer", . Therefore, it was meaningful to describe the symptoms leading the patient to the health care system (paper 1).

Randomization is the "gold standard" in clinical study design. However, patient selection is one of the limitations in randomized trials, which may make the studied patients non-representative for the whole patient population and the results less valid. The majority of EOC patients are not enrolled in randomized clinical trials. In the United States, only $6 \%$ of these patients were enrolled in treatment trials ${ }^{144}$. During 2003, 49 out of $268(18 \%)$ stage II - IV EOC patients were enrolled in primary chemotherapy trials in Norway $^{145}$. This demonstrates the need for a population-based prospective approach in order to overcome possibly biased results (papers $1-3$ ). Knowledge of the patient's disease based on the whole population with the specific disease within a geographic region is called "population adjusted clinical epidemiology"146.

Classical epidemiology deals with risk factors for development of disease, while clinical epidemiology describes individuals' already experiencing disease. Rothman defined clinical epidemiology as: “....the study of illness outcomes in persons seen by providers of health care" ${ }^{\text {147 }}$. In the present thesis the intention was to use a clinical epidemiological approach to demonstrate differences in outcome for different groups of EOC patients. The underlying research-question was whether patients received optimal treatment within the existing Norwegian health care system (papers $1-3$ ).

The relation between treatment levels and patient outcome is important in a public health perspective. The health care providers and policy makers might organize the health care in a more appropriate manner on basis of clinical epidemiological knowledge.

In the United Kingdom the politicians wish welcome the development of multidisciplinary care, which might better the outcome for a variety of patient groups ${ }^{148}$. This perspective also includes increased knowledge of tumour biology, which might improve the treatment (paper 4). 


\section{MATERIALS AND METHODS}

\section{Study population}

The present thesis comprised 907 patients. Paper 1 enrolled all patients with EOC and BOT $(\mathrm{n}=623)$ while paper 2 included stage IIIC EOC patients $(\mathrm{n}=198)$ diagnosed in 2002. Paper 3 comprised stage IIC to IV EOC patients $(n=371)$ with primary diagnosis $2002(\mathrm{n}=186)$ and $2003(\mathrm{n}=185)$ receiving chemotherapy after surgery. Many patients $(\mathrm{n}$ $=384$ ) were enrolled in more than one of the papers 1 to 3 (Table 4). In paper 4, S-BOT patients with and without non-invasive implants were selected randomly from the Cancer Registry diagnosed between 1985 and $1995(\mathrm{n}=99)$. Paper 1 and 4 addressed different aspects of diagnostic procedures, while paper 2 and 3 concerned treatment outcome (Table 3).

\section{Organization and data collection}

\section{OVANOR registry (Table 2)}

An important tool in the present thesis was the development of a prospective, population-based, clinical registration system for EOC, non-EOC and BOT in Norway. All epidemiological data were collected in accordance with the Cancer Registry regulations: $\S 1-7^{149}$.

A reference group of physicians from TH and NTH was established in 2000. The Cancer Registry invited physicians from all gynaecological units in Norway to participate in the reference group. It consisted of 18 physicians of whom one was a pathologist; one oncologist, one specialist in laboratory medicine, and the rest were gynaecologists. The reference group took part in the planning of a questionnaire, which was sent to all 41 gynaecological units in Norway (Appendix 12.3). According to the answers, there were large variations in the treatment of patients with EOC in Norway ${ }^{150}$. An extended clinical form for ovarian cancers was designed (Appendix 12.2). This clinical form replaced the standard Cancer Registry form. An electronic database was programmed in Firebird based on the data elements from the extended clinical form.

The physicians responsible for medical examinations and treatment at the hospitals filled in the extended clinical form after January 1, 2002. The clinical form was returned to the Cancer Registry together with a copy of the surgical report within two months after the primary diagnosis. The pathological laboratories sent a mandatory copy of the pathological and/or cytological report to the Cancer Registry. In cases of missing data, the medical report was requested. Information on chemotherapy was collected from the patient 
administrative system for all hospitals in Norway. In some cases additional information was supplied from laboratory results, image description, and referral letter. The cause of death registry was used to obtain cause of death and date of death. Last observation and emigration were aquired from the National Population Registry ${ }^{151}$. A reminder was sent to the hospital if the new clinical form or surgical report was missing. The above mentioned data elements comprised the OVANOR registry (Table 2). Ovarian cancer patients enrolled in the main Cancer Registry were compared with patients enrolled in the OVANOR registry in order to identify missing patients in the latter registry and vice a versa. All missing patients were then enrolled in the OVANOR registry.

Table 2. Flow chart of information flow from different health care levels to the Cancer Registry of Norway, paper 1-4

\section{Health care level}

\begin{tabular}{lll}
\hline Gen. practitioner & Teaching hospitals (TH) & National registries \\
Gen. gynaecologist & Non-teaching hospitals (NTH) &
\end{tabular}

Clinical form*

Surgical report*

Pathological report*

Medical report*

Patient

Referral letter $2 * *$

Patient administrative system**

Laboratory result**

Image description**
Cause of Death

Registry*

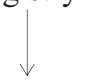

Cancer Registry

of Norway

National Population

Registry*

*Basic sources, **Additional sources

\section{BOT registration}

The patients enrolled in paper 4 were identified in the main database of the Cancer Registry on basis of tumour localization, ovary (ICD10: C56) ${ }^{152}$ and serous papillary borderline tumour with and without corresponding non-invasive implants (SNOMED codes: $8440,8441,8442,5850,8451,8452,8462,8560)^{153}$. The paraffin embedded tissues were collected from 19 pathological departments in Norway. The paraffin-embedded blocks were assigned a unique block-number (200 to 828) and an archive card was filled in for each paraffin block with the block number and patient ID-number (1 to 158). All the paraffin-embedded tissues were stained using the immunohistochemical method at the laboratory for pathology, the Norwegian Radium Hospital. Two pathologists (JMN, AB) independently scored the immunohistochemical stained slides. Information about medical 
history, symptoms and treatment were collected from old clinical forms and pathological reports in the main Cancer Registry database. Surgical reports and medical records were requested from the hospitals where the primary treatments were performed. The current thesis is based upon data from OVANOR registry and the main database of the Cancer Registry.

\section{Study design and follow-up (Table 3)}

Paper 1 is a population-based, cross-sectional register study of EOC and BOT. Paper 2 and 3 were prospective, population-based cohort studies of EOC, where the patients were followed to death, last observation or emigration. According to data from the Cause of Death Registry ${ }^{151}$, the cause of death was ovarian cancer (ICD-10, C56) ${ }^{152}$ for all patients, but one, who died of lung cancer in 2002. This patient was omitted from the analyses. The survival in paper 2 and 3 was measured as cancer specific survival.

Paper 4 is considered a retrospective, population-based study of S-BOT comparing two groups (group with non-invasive implants and group without non-invasive implants) with regard to immunohistochemical staining (MMP-2, MMP-14, TIMP-2, VEGF, VEGFR-1, and VEGFR-2) of the the primary ovary tumours and the non-invasive implants. The cohort was followed to recurrence or January 1, 2006. Data of recurrence were obtained from surgical reports and pathological reports archived at the Cancer Registry. The survival was measured as disease-free survival. 
Table 3. Overview of design and analytic models, paper 1-4

\begin{tabular}{|c|c|c|c|c|}
\hline Characteristics & $\begin{array}{l}\text { Paper } 1 \\
\text { Symptoms and referral }\end{array}$ & $\begin{array}{l}\text { Paper } 2 \\
\text { Surgery and } \\
\text { operating hospital }\end{array}$ & $\begin{array}{l}\text { Paper } 3 \\
\text { Surgery-chemo. } \\
\text { interval }\end{array}$ & $\begin{array}{l}\text { Paper } 4 \\
M M P \text { expression in } S_{-} \\
B O T\end{array}$ \\
\hline Design & $\begin{array}{l}\text { Population-based, } \\
\text { cross sectional register } \\
\text { study with follow-up to } \\
\text { first treatment }\end{array}$ & $\begin{array}{l}\text { Prospective, } \\
\text { population-based } \\
\text { register study with } \\
\text { follow-up to death } \\
\text { or last observation }\end{array}$ & $\begin{array}{l}\text { Prospective, } \\
\text { population-- } \\
\text { based register } \\
\text { study with } \\
\text { follow-up to } \\
\text { death or last } \\
\text { observation }\end{array}$ & $\begin{array}{l}\text { Retrospective pop.-- } \\
\text { based register and } \\
\text { laboratory } \\
\text { study with follow-up to } \\
\text { recurrence or last } \\
\text { observation }\end{array}$ \\
\hline Analytic method & $\begin{array}{l}\text { Multinominal logistic } \\
\text { regression } \\
\text { Nonparametric tests of } \\
\text { the median }\end{array}$ & $\begin{array}{l}\text { Binominal logistic } \\
\text { regression } \\
\text { Cox proportional } \\
\text { hazard model } \\
\text { Kaplan Meier } \\
\text { Log rank test }\end{array}$ & $\begin{array}{l}\text { Cox proportional } \\
\text { hazard model } \\
\text { Kaplan Meier } \\
\text { Log rank test }\end{array}$ & $\begin{array}{l}\text { Mann-Whitney: } \\
\text { non parametric } \\
\text { independent sample test } \\
\text { Wilcoxon: } \\
\text { non parametric } \\
\text { two related sample test } \\
\text { Kaplan Meier } \\
\text { Log rank test }\end{array}$ \\
\hline Start of follow-up & $\begin{array}{l}\text { Date of } 1 . \text { symptom } \\
\text { Date of } 1 . \text { dr.consult. } \\
\text { Date of admission }\end{array}$ & $\begin{array}{l}\text { Date of primary } \\
\text { surgery }\end{array}$ & $\begin{array}{l}\text { Date of } \\
\text { 1.chemotherapy } \\
\text { cycle }\end{array}$ & Date of primary surgery \\
\hline End of follow-up & $\begin{array}{l}\text { Date of } 1 \text {. operation } \\
\text { Date of } 1 . \text { chemo.cycle } \\
\text { or December } 31,2002\end{array}$ & $\begin{array}{l}\text { Date of death or } \\
\text { March } 31,2004\end{array}$ & $\begin{array}{l}\text { Date of death or } \\
\text { May } 31,2005\end{array}$ & $\begin{array}{l}\text { Date of recurrence or } \\
\text { January } 1,2006\end{array}$ \\
\hline Measure of effect & & $\begin{array}{l}\text { Hazard ratio }(\mathrm{HR}) \\
\text { Odds ratio }(\mathrm{OR})\end{array}$ & $\begin{array}{l}\text { Hazard ratio } \\
\text { (HR) }\end{array}$ & \\
\hline Survival & & $\begin{array}{l}\text { Cancer specific } \\
\text { death }\end{array}$ & $\begin{array}{l}\text { Cancer specific } \\
\text { death }\end{array}$ & Disease-free survival \\
\hline
\end{tabular}

\section{Variables (Table 4)}

Prognostic variables (factors) identified at time of primary diagnosis were as follows: residual disease, histologic type (serous or nonserous), grade of differentiation ${ }^{154}$, degree of atypia, presence of ascites, age, physical performance status ${ }^{33}$, serious comorbidity (defined in paper 3), postoperative chemotherapy, serum CA-125, and DNA ploidy.

\section{Explanatory variables}

Clinical variables

The explanatory variables were different among the papers depending on the aim. The symptoms were grouped into 10 categories based on information in text files from the previously described sources (Table 2). Hospital units were defined as the first unit the patient was referred to (GYN, surgical, medical and other units). The hospital level was divided into the two categories TH and NTH (page 14). The specialty of the operating physicians was based on the specialty approval from the Ministry of Health in Norway. Being a specialist in gynaecological oncology was defined as having worked at least one year at the Norwegian Radium Hospital, because no formal specialty in gynaecological 
oncology exists in Norway. The interval between surgery and first chemotherapy cycle (SCI) was defined as date from primary surgery to date of first chemotherapy cycle.

Table 4. Overview of patient population and main variables and design, paper 1-4

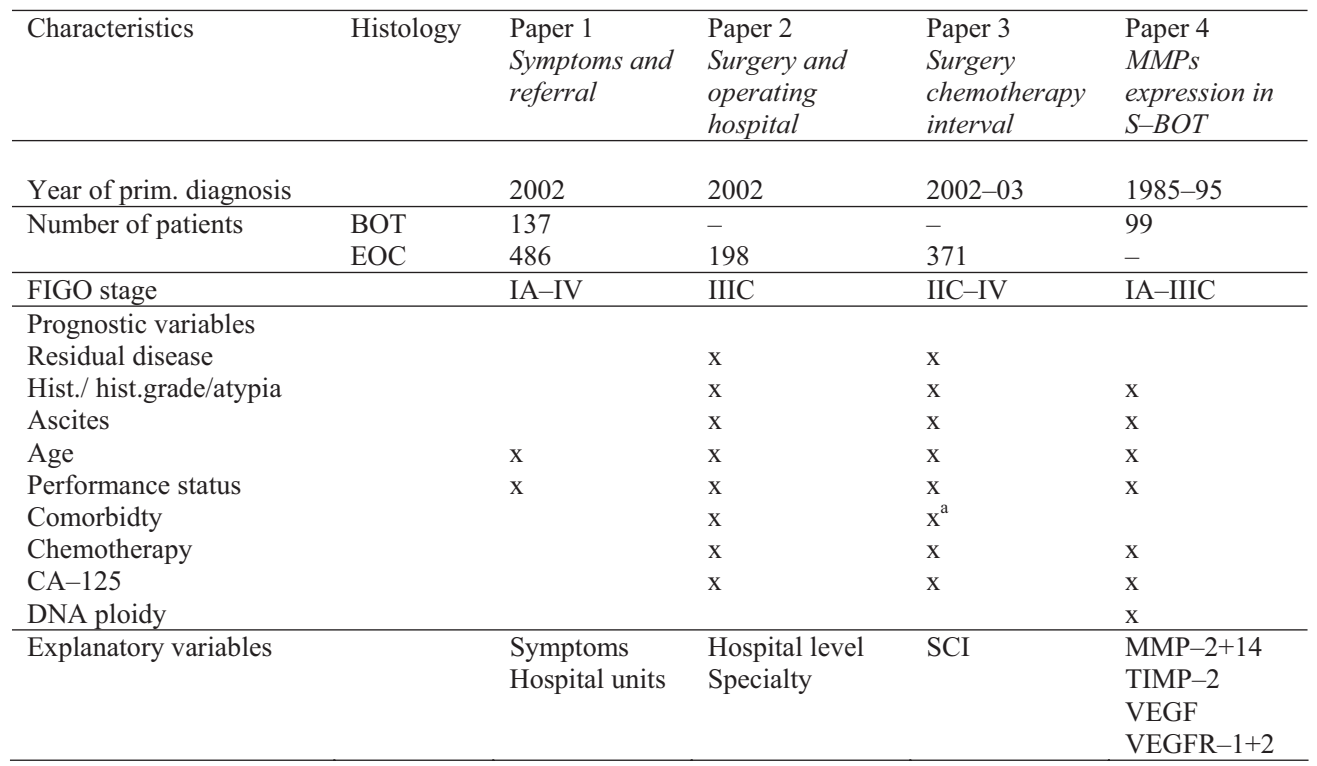

${ }^{a}$ Analysed, not published

Immunhistochemical variables (Table 5)

In paper 4 we examined MMP-2 and MMP-14 antibodies and their inhibitors (TIMP-2) together with VEGF and VEGFR. Five monoclonal antibodies (MMP-2, MMP14, TIMP-2, VEGF, and VEGFR-2), and one polyclonal antibody (VEGFR-1) were used for staining. Appropriate negative and positive (placenta) controls were used in each staining run (Table 5).

Table 5. Characteristics of immunhistochemical antibodies, paper 4

\begin{tabular}{llll}
\hline Antibody & Clone & Animal & Company \\
\hline MMP-2 & Mono & Mouse & Lab Vision \\
MMP-14 & Mono & Rabbit & Lab Vision \\
TIMP-2 & Mono & Rabbit & Lab Vision \\
VEGF & Mono & Mouse & Santa Cruz \\
VEGFR-1 & Poly & Rabbit & Santa Cruz \\
VEGFR-2 & Mono & Mouse & Chemicon \\
\hline
\end{tabular}




\section{Quality of data "Cross-checking procedures"}

In cases where basic data were missing, a reminder was sent to the hospital. The data elements used in paper 2 were returned to the hospitals where primary surgery was performed (TH: Universitetssykehuset i Nord Norge, St. Olav Hospital, Haukeland universitetssjukehus, Rikshospitalet-Radiumhospitalet; NTH: Sykehuset Østfold, Stavanger universitetssjukehus). The majority $(\mathrm{n}=124,63 \%)$ of the patients were operated at these hospitals and they had the first chemotherapy course at TH. The physicians responsible for the treatment checked the accuracy of data and returned the corrected data. Three of 313 dataelements (1\%) contained errors. One hospital was coded as NTH (correct: TH), CA125 was coded in the interval 36-150 (correct: > 150), and performance status according to WHO as 0 (correct: 1). The data errors were corrected in the OVANOR registry. After correction, less than $1 \%$ of the dataelements used in the analyses may contain errors, if we presumed that the data not cross-checked also contained $1 \%$ errors. All immunhistochemical data were coded directly into SPSS. The data completeness was high (61-100\% in paper $1,82-100 \%$ in paper $2,92-100 \%$ in paper 3). In the retrospective S-BOT study, the completeness was lower (35-100\%, Appendix 12.4).

If the information from the clinical form was inconsistent with information from other sources (surgical, pathological reports and medical records) the data was changed according to the presumed correct value. Example: the clinician staged the tumour to IIIC and the cytologist discovered malignant cells in the pleural effusion, the stage was then corrected to IV in the OVANOR registry (Appendix 12.1) ${ }^{61}$.

\section{Statistical analyses (Table 3)}

All analyses were performed with SPSS for Windows (versions 11.5 - 12.01, Chicago, IL). Chi-square tests were used in the cross tables. To test correlation between prognostic variables, Spearman correlation factor was calculated. The survival pattern between various groups was displayed as Kaplan-Meier plots. The log-rank test was used to calculate differences in survival between the various groups. The Cox proportional hazard model was used to estimate the effect (as hazard ratios, HR) of the prognostic variables on survival. A binominal logistic regression model was used to examine the odds ratio (OR) associated with optimal chemotherapy. 
In paper 4 the Kappa coeffecient was used to test the agreement between two independent pathologists' scoring of immunhistochemical stained slides.

Three comparisons were made, (I) nonimplant ovaries with implant ovaries, (II) nonimplant ovaries with implants, and (III) implant ovaries with corresponding implants (Figure 7). In analyses I and II, the Mann-Whitney test was used to test the differences in immunhistochemical staining between the implant and nonimplant groups. In analysis III the Wilcoxon signed rank test was used to test the difference between primary tumours and their associated implants.

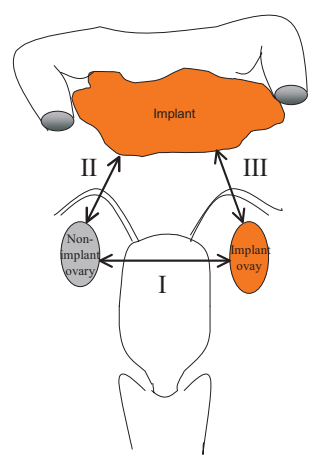

Figure 7. Scheme of tumour spread

\section{SUMMARY OF EACH PAPER}

\section{Paper 1}

All women diagnosed with epithelial, ovarian, tubal, and peritoneal cancer (EOC, $n$ $=486$ ), and borderline ovarian tumours (BOT, $\mathrm{n}=137$ ) in Norway during 2002 were enrolled in this study.

Sixty-one percent of women with EOC were referred to GYN units, while $24 \%$ were referred to surgical and $14 \%$ to medical units. 'Abnormal menstrual or vaginal bleeding or discharge', were more frequent symptoms among patients referred to GYN units. 'Abdominal pain or discomfort' was the most common symptom among women referred to GYN and surgical units while women suffering from one or more of the symptoms 'bowel irregularity', 'pain outside the abdominal cavity', 'persisting fatigue or 
weight loss', 'respiratory difficulties' and 'other symptoms' were most likely to be referred to a medical unit.

A treatment delay was experienced by women referred to surgical and medical units compared to those referred to GYN units (mean, 20 and 24 versus 11 days). Fortyfive percent of women with EOC visited their general practitioner or private gynaecologist within three months from onset of first symptom. The physicians referred the patients to the hospital within one year from the first consultation in $94 \%$ of the cases.

\section{Paper 2}

All stage IIIC EOC patients $(n=198)$ that underwent primary surgery followed by chemotherapy $(n=175)$ or having three courses of neoadjuvant chemotherapy $(n=23)$ during 2002 were selected.

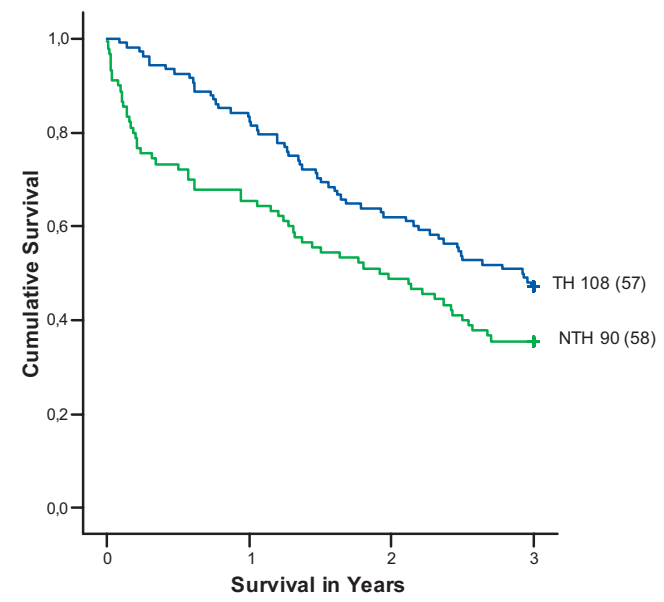

Figure 8. Kaplan-Meier survival curves for advanced ovarian/peritoneal/tubal cancer (EOC) by hospital level where surgery is performed. Log-rank test, $P=0.02$. TH, Teaching hospitals, number of patients treated 108, (57 patients are dead at end of followup). NTH, Non-teaching hospitals, number of patients treated 90 (58 patients are dead at end of follow-up)

The short-term survival benefit at 450 days for patients operated at TH compared to NTH was $17 \%$. After 3 years of observation a survival benefit for patients operated at TH still exist (Figure 8). The risk of death within 600 days was 1.8 (HR) times higher at NTH compared to TH after simultaneously adjustment for seven prognostic factors. The women operated on by specialized compared to general gynaecologists had a $20 \%$ 
increased survival at 450 days $(P<0.0001)$. We confirmed that tumour reduction to no residual disease significantly improved survival.

\section{Paper 3}

All EOC patients in stages IIC - IV $(n=371)$ during 2002 and 2003 were selected. These patients underwent primary surgery and were then treated at different time intervals by chemotherapy.

No difference in survival between patient groups was seen when time between surgery and start of chemotherapy (SCI) was divided into quartiles. The group of patients with SCI less than six weeks had inferior survival if they had residual disease compared to those without residual disease after surgery, adjusted HR $=2.4$. However, in the patient groups with SCI more than six weeks, there was no significant difference in survival between patients with and without residual disease. Unadjusted, HR $=1.6$ adjusted HR = $1.4)$.

\section{Paper 4}

The population comprised 99 patients with S-BOT with primary diagnosis between 1985 and 1995, 44 with non-invasive implants and 55 without non-invasive implants.

Strong positive MMP-2 staining was found more frequently in women with primary SBOT with non-invasive implants (76\%) compared to those without implants $(53 \%, p<$ 0.05). Expression of MMP-2, MMP-14, and TIMP-2 was similar in primary tumours and in their corresponding non-invasive implants. Most tumours had no VEGF expression (84 $\%$ versus $82 \%$ ), while moderate to strong expression of VEGFR-1 and VEGFR-2 was detected in $79-94 \%$ of tumours from both patient groups (nonsignificant). Three patients relapsed as invasive and four as borderline tumours. 


\section{DISCUSSION}

\section{Methodological issues}

The data elements were precisely defined before starting the studies. The completeness and quality of data was continuously secured by reminders and crosschecking procedures. Diagnostic procedures and treatment of S-BOT might have changed during the time period 1985 to 1995 . In the period 2002 to 2003 diagnostic procedures, surgery and chemotherapy, did not change much, therefore the results were reliable for all patients studied. In study 2 and 3 the observation time was short, however, EOC patients treated with combination of paclitaxel have a median survival of aproximatly 32 months ${ }^{107}$ therefore short observation time is sufficient to record differences in survival among the study group of advanced EOC patients.

Precision is defined as lack of random error. Two ways of improving precision are described: the first by increasing the size of the study and the second by increasing the efficiency with which information is obtained from the patients ${ }^{147}$.

The number of patients studied in the present thesis was relatively small, but large enough to give answers to the aims of the thesis. In epidemiological, prospective population-based studies there is no need for large studies, if the differences in outcome between the patient groups are substantial and the quality of the data is good.

The information obtained from each patient is precise because of numerous data sources and cross-checking procedures. The proportion of missing data was decreased from paper 1 to 3 because the data collection had been carried out for another year, supplying more data. The sample size in paper 4 was larger than the estimated number of 28 patients needed in each group calculated before study start.

The proportion of missing data was higher in paper 4 due to the retrospective design and long follow-up.

Selection bias is present when the study population is not representative for the population in focus ${ }^{147}$.

The Cancer Registry contains information on all patients with invasive cancer in Norway, resulting in little selection bias ${ }^{155-157}$. However, there might be a selection bias in referral to the various hospitals. During 2002 and 2003 the hospitals in health region South and some of the hospitals in region East and West referred the patients to the Norwegian Radium Hospital. Except for the latter hospital, the other hospitals making up the TH 
group had emergency services. The patients referred as an emergency were equally distributed between the groups TH and NTH (emergencies: $9 \%$ ), hence the emergency help did not present any selection bias.

Information bias in evaluating an effect can occur from errors in obtaining the information and measurements of subjects ${ }^{147}$.

A misclassification of epithelial ovarian cancers might occur since not all pathologists have specialized knowledge about gynaecological pathology. A Norwegian study showed that the completeness of ovarian cancer is close to $100 \%$ in the Cancer Registry when a second pathologist reviewed the specimen ${ }^{157}$. The deficiency in reporting of prostate cancer was less than $1 \%$. The validity control revealed errors in only $0.5 \%$ of the data elements ${ }^{155}$, which was in accordance with the findings of EOC in the present thesis. Metastasis from other primary sites might also have been coded as primary ovarian cancer, but this misclassification is a minor problem.

The non-operated patients had a higher risk of being misclassified than those operated. In 13 out of 486 patients $(<3 \%)$ no histological or cytological information were available (Table 6). This misclassification might play a role in paper 1, since patients that were not operated on were included in the analyses (53 out of 486). However, none of the not operated patients were included in paper 2 to 4 .

Table 6. The basis for the diagnosis in the Cancer Registry among patients with invasive epithelial ovarian/tubal and peritoneal cancer with primary diagnosis 2002, $n=486$, paper 1

\begin{tabular}{lll}
\hline Diagnostic characteristics & $\begin{array}{l}\text { Patients operated } \\
\mathbf{n}=\mathbf{4 3 3}(\mathbf{\%})^{\mathbf{a}}\end{array}$ & $\begin{array}{l}\text { Patients not operated } \\
\mathbf{n}=\mathbf{5 3}(\mathbf{\%})^{\mathbf{a}}\end{array}$ \\
\hline Histology & $431(99.5)$ & $15(28)$ \\
Cytology, only & $2(0.5)$ & $21(40)$ \\
Autopsy, only & 0 & $4(8)$ \\
Missing/not analyzed & 0 & $13(25)$ \\
\hline Sonography, and/or & & $53(100)^{\mathrm{b}}$ \\
CT and/or MRI & $424(98)$ & 0 \\
Missing & $9(2)$ & $41(77)$ \\
\hline CA-125 & $355(82)$ & $12(23)$ \\
Missing & $78(18)$ & $22(42)$ \\
\hline CEA & 0 & $31(58)$ \\
Missing & $433(100)$ & $1(2)$ \\
\hline Clinical diagnosis only & 0 & $52(98)$ \\
Clinical and other diagnostic & $433(100)$ & \\
information &
\end{tabular}


Confounding occurs when an estimate of the association between an exposure and an outcome is mixed up with the real effect of another exposure on the same outcome, the two exposures being correlated ${ }^{158}$.

Confounding must be a relative strong risk factor before the outcome is changed ${ }^{147}$. We did not identify any important confounders.

External validity (generalizability) is accomplished if the conclusions in a specific study can be applied on a group of patients not enrolled in the study ${ }^{147}$.

We used population-based studies to accomplish high external validity. The findings in the thesis will be valid for similar patient populations. Although, the findings might not have external validity to populations with other genetic dispositions or treated in different health care systems.

\section{Discussion of the results}

\section{Paper 1}

The frequency of specific symptoms in paper 1 was lower than in an investigation based on a survey sent to ovarian cancer patients ${ }^{8}$. The use of patient's self-report might give higher frequency of symptoms than information based on medical records ${ }^{159}$. The incidence of having any symptom did not differ much between our findings (94\%) and a previous investigation by Goff $(95 \%)^{8}$. Vine et al. reported that $90 \%$ of EOC patients had symptoms ${ }^{160}$. Information on symptoms based on medical records did probably give valid data compared to patient questionnaires. The median duration of symptoms was longer in the latter study than in ours, 4 compared to 2.4 months $^{160}$. A standardarized in-person questionnaire was conducted in the latter investigation. There might be a recall bias from patients or lack of appropriate reporting from the physician in our work. However, the results did not differ much between other studies and ours, thus this bias is of minor importance.

The majority of EOC patients had symptoms before referral which did not support the statement of ovarian cancer as "silent killer" 8 . Further, most of the early stage EOC patients had symptoms as well, $87 \%$ in our study compared to $90 \%$ in a recently published study by Latifeh ${ }^{161}$. A textbook ${ }^{7}$ maintained that $75 \%$ of women presenting with ovarian cancer had symptoms, while we found $94 \%$ of women with EOC and $75 \%$ with BOT had symptoms . BOT patients reported a lower frequence of symptoms and they saw their general practioner later after onset of symptoms compared to EOC patients, which 
might be explained by the lesser tumour spread at primary diagnosis (Figure 2) and slow tumour growth. These findings was in accordance with a previous study ${ }^{160}$.

Many patients were initially referred to surgical and medical units, probably because the physician interpreted the symptoms ('bowel irregularities', 'pain outside the abdomen', 'repiratory difficulties') as representing a non-gynaecological disease. A treatment delay was observed for patients that were first referred to surgical and medical units, probably due to a delay in diagnosis.

Vaginal bleeding or discharge was seen in $14 \%$ of the women with EOC and $16 \%$ of those with BOT. This was in contrast to a Sweedish textbook ${ }^{6}$, where vaginal bleeding was reported in only $5 \%$ of the cases. Patient information obtained from physicians' recordings were probably less accurate than information obtained from patient questionnaires $^{162 ; 163}$. In spite of this, the frequency of symptoms based on physician' recordings were higher in the present thesis than in the textbooks. May be there is a need to rewrite these textbooks.

Only patients with epithelial ovarian cancers were enrolled in paper 1, and we do not know how many patients seeing their primary physician with the same symptoms having other diseases. General practioners in East London referring women to screening because of symptoms suspect of EOC found that patients with abdominal pain and distention without non-abdominal symptoms were more likely to have EOC than patients with both abdominal and non-abdominal symptoms ${ }^{164}$.

\section{Paper 2}

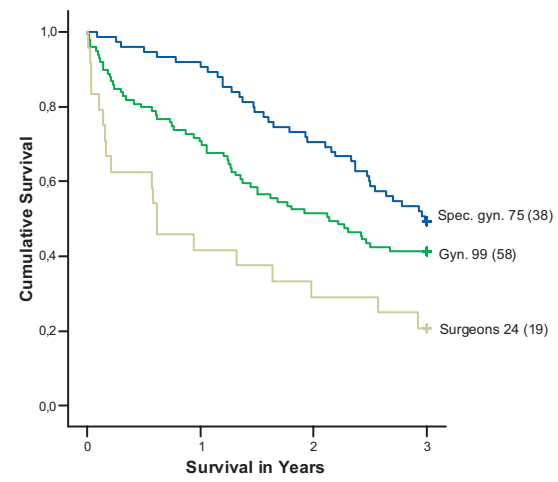

Figure 9. Kaplan-Meier survival curves for advanced ovarian/peritoneal/tubal cancer (EOC) by specialty of operating physicians performing initial surgery. Log-rank test, $P<$ 0.001. Specialist gynaecologist, number of patients treated 75, (38 patients are dead at end 
of follow-up). Gynaecologist, number of patients treated 99 (58 patients are dead at end of follow-up). Surgeons, number of patients treated 24, (19 patients are dead at end of follow-up)

The present thesis comprised the first prospective study to demonstrate improved survival of EOC patients treated at TH compared to NTH and improved survival when treated by specialist oncology gynaecologists compared to general gynaecologists (Figure 9). The hospital level and surgical skills influenced the survival outcome for EOC patients. Other authors came to the same conclusions based on retrospective study designs ${ }^{72 ; 90}$. The present study had a shorter observation time compared to Junor and Engelen. After a follow-up of three years there is still a significant difference in survival between TH and NTH (Figure 8 and 9).

Other investigators have shown that more extensive surgery is carried out at $\mathrm{TH}$. The operating physicians at TH performed lymphadectomy more often than physicians at $\mathrm{NTH}^{165}$. In paper 2 we defined stage IIIC on basis of positive lymph nodes as lymph nodes equal or larger than $2 \mathrm{~cm}^{61}$. In our paper, ten patients were staged IIIC on basis of positive lymph nodes $(\geq 2 \mathrm{~cm})$, eight of these patients were operated at TH and two at NTH. When these patients were omitted from the analyses, the survival did not change significantly. The more frequent upstaging of EOC patients at $\mathrm{TH}$ could not explain the difference in survival between TH and NTH. However, a recent study demonstrated the necessity for stratifying patients classified as having stage IIIC disease based on nodal disease only when comparing outcomes ${ }^{166}$.

In the present study the postoperative mortality was $5.6 \%$. This was in accordance with investigations on colorectal cancer ${ }^{167 ; 168}$. In an investigation on EOC the postoperative mortality was only $1 \%{ }^{169}$. This low mortality might be due to patient selection. A higher postoperative mortality (death within 30 days after operation) at one treatment level might invalidate the analyses. There were more patients dying short time after surgery in the NTH group in our study $(\mathrm{NTH}, \mathrm{n}=10$ versus $\mathrm{TH}, \mathrm{n}=1)$. Allthough, if these patients were excluded from the analyses, the hazard ratio did not change significantly.

In the present paper a comorbidity score with two levels were used for adjustments. This score was not evaluated against mortality. We therefore calculated a comorbidity score later, based on a scale $(0-4)$ that was evaluated against the mortality in a breast cancer population (Charlson score) ${ }^{170}$. The patients in paper 2 had increased mortality with increased Charlson score (except for score 2). This score was distributed equally between 
the hospital levels (TH versus NTH). The Charlson score did not change the hazard ratios after adjusting for all prognostic factors.

The most important prognostic factor was when the operating physician achieved no recidual disease, which was in accordance with other investigators ${ }^{68-73 ; 171}$. Aletti demonstraded that overall, residual disease was the only independent predictor of survival $^{171}$. Further we demonstrated differences in survival among the TH (Figure 10). All TH have a potential to improvement. The number of patients' optimally debulked $(0 \mathrm{~cm}$ residual disease) might be increased at all $\mathrm{TH}$ (Table 7). One way to aceive this goal is to incorporate extensive upper abdominal procedures into the operative strategy. This may increase the rate of primary optimal cytoreduction without increasing perioperative morbidity and mortality ${ }^{172}$

Table 7. The residual disease achieved at the different TH among patients with invasive epithelial ovarian/tubal and peritoneal cancer (EOC) with primary diagnosis 2002, $n=$ 198, paper 2 (Pearson $P=0.015$ )

\begin{tabular}{llllll}
\hline $\begin{array}{l}\text { Residual } \\
\text { disease }\end{array}$ & TH1 & TH2 & TH3 & TH4 & NTH \\
\hline $0 \mathrm{~cm}$ & $18(40)$ & $8(35)$ & $4(14)$ & $2(18)$ & $15(17)$ \\
$>0 \mathrm{~cm}$ & $27(60)$ & $15(65)$ & $25(86)$ & $9(82)$ & $75(83)$ \\
\hline
\end{tabular}

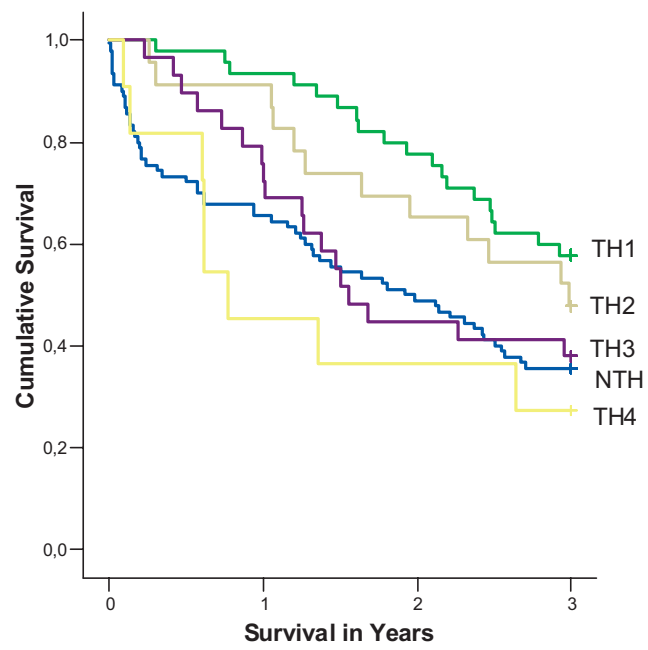

Figure 10. Kaplan-Meier survival curves for advanced ovarian/peritoneal/tubal cancer (EOC) by TH and NTH. Log-rank test, $P=0.02$. TH1, number of patients treated 45, (19 
patients are dead at end of follow-up). TH2, number of patients treated 23 (12 patients are dead at end of follow-up). TH3, number of patients treated 29, (18 patients are dead at end of follow-up), TH4, number of patients treated 11, (8 patients are dead at end of follow-up), and NTH, number of patients treated 90, (58 patients are dead at end of follow-up)

\section{Paper 3}

In a murine model the greatest effect on residual tumour growth and survival occurred when chemotherapy was given at day of surgery and not as effective if given 7 days after surgery ${ }^{109}$. In retrospective human studies the length of SCI did not influence survival $^{110 ; 111}$. The present prospective and population-based study confirmed the findings in the previous human studies. However, no human studies have compared chemotherapy given at day of surgery compared to chemotherapy given several days after surgery as done in the murine model ${ }^{109}$.

The six weeks SCI was used because patients waiting more than six weeks often are excluded from chemotherapy phase III trials. When dividing the SCI into more equally distributed groups ( $<4$ weeks, $n=198$ and $\geq 4$ weeks, $n=178$ ), no major changes were seen in the Cox estimates. The majority of patients having chemotherapy within four weeks received their first cycle before leaving the hospital after surgery. A previous study used quantiles of intervals ${ }^{111}$, while another study used intervals shorter or longer than the $\operatorname{median}^{110}$.

In the survival analyses we chose follow-up from date of first chemotherapy cycle and not date of primary surgery, because the patients treated with chemotherapy more than six weeks after surgery would otherwise have a guaranteed survival of six weeks and could give bias to the analyses.

New analyses were made to illuminate the question why patients (76 out of $371 \mathrm{had}$ SCI $>6$ weeks) had delayed SCI. Hospital level and co-morbidity (defined in paper 2, no co-morbidity, $\mathrm{n}=335$, co-morbidity, $\mathrm{n}=39$ ) were introduced in the analyses. When these two variables additionally were corrected for in the Cox analyses, only small changes were seen in the estimates. The conclusions in the paper were not altered by these new analyses (Table 7). These results were not published in the paper. 
Table 8. Hazard ratios (HR, $95 \%$ confidence intervals, CIs) for patients with advanced ovarian, tubal or peritoneal cancer (EOC) who received chemotherapy at different intervals after primary surgery (SCI); Cox regression, paper 3

\begin{tabular}{|c|c|c|c|c|c|c|c|c|c|}
\hline $\begin{array}{l}\text { Residual } \\
\text { disease } \\
\text { status }\end{array}$ & $\begin{array}{l}\begin{array}{l}\text { Interval } \\
\text { (weeks) }\end{array} \\
\text { SCI }\end{array}$ & $\begin{array}{l}\text { No. } \\
\text { patients }\end{array}$ & of & Unadj. & CI & $\begin{array}{l}\text { Adjusted for } \\
7 \text { prognostic } \\
\text { Variables } \\
\text { HR }\end{array}$ & CI & $\begin{array}{l}\text { Adjusted for } \\
9 \text { prognostic } \\
\text { Variables } \\
\text { HR } \\
\end{array}$ & CI \\
\hline \multirow{2}{*}{ None } & $<6$ & 82 & & 1 & & 1 & & 1 & \\
\hline & $\geq 6$ & 24 & & 1.86 & $0.75-4.61$ & 1.35 & $0.51-3.56$ & 1.53 & $0.57-4.05$ \\
\hline \multirow{2}{*}{$\begin{array}{l}\text { Residual } \\
\text { disease }\end{array}$} & $<6$ & 213 & & 3.66 & $2.09-6.40$ & 2.36 & $1.22-4.57$ & 2.55 & $1.31-4.96$ \\
\hline & $\geq 6$ & 52 & & 2.67 & $1.35-5.28$ & 1.64 & $0.76-3.57$ & 1.69 & $0.77-3.71$ \\
\hline
\end{tabular}

Patients operated at $\mathrm{TH}$ received their first chemotherapy cycle earlier than patients operated at NTH (24 versus 36 days, Table 9). This was probably due to the time delay when referring the patients from NTH to TH after surgery. The first chemotherapy cycle is mostly given at $\mathrm{TH}$.

Table 9. Time from surgery to first chemotherapy cycle, paper 3

\begin{tabular}{lll}
\hline & $\begin{array}{l}\text { Time from surgery to first } \\
\text { chemotherapy cycle } \\
\text { TH }(\mathbf{n}=\mathbf{1 9 4})\end{array}$ & $\begin{array}{l}\text { Time from surgery to first } \\
\text { chemotherapy cycle } \\
\text { NTH (n= 177) }\end{array}$ \\
\hline Mean (days) & 24.0 & 36.3 \\
Median (days) & 20 & 35 \\
Range (days) & $5-87$ & $1-118$ \\
\hline
\end{tabular}

${ }^{1}$ Independent sample t-test, $\mathrm{P}<0.001$

A recent study showed that patients debulked to less than $2 \mathrm{~cm}$ had a longer progression free survival if the patients had less extensive disease at the onset of chemotherapy ${ }^{79}$. Makar found that patients in stages IIIA-B with no residual disease have improved overall survival compared to patients in stage IIIC with no residual disease after primary surgery ${ }^{173}$. The present thesis gave weak support to this finding. The survival was slightly improved in the group with less extensive disease before surgery. In the present thesis a non-significant increased risk of dying was seen in stage IIIC with no residual disease after primary surgery after correction for 7 prognostic factors in the Cox analyses. Unadjusted HR = 1.2 (CI 0.5-2.7) and adjusted HR = 2.3 (CI 0.7-7.6).

It would be of interest to assess the impact of delayed chemotherapy on time to recurrence rather than time to death. The cancer specific death might be influenced by many other factors than disease-free survival, including choice of therapy for recurrent disease. Reassessment of the data using this endpoint might be meaningful to perform in later analyses, but data on recurrence was not available in the present paper (page 45). 


\section{Paper 4}

Many S-BOT recurrences occur several years after primary diagnosis. In order to have a follow-up on all patients of at least ten years, patients diagnosed between 1985 and 1995 were selected. Long follow-up secured the majority of recurrences to be identified. A follow-up of at least 10 -years is recommended by other authors ${ }^{174}$.

One limitation in study design was that lack of staining might indicate that antigens had vanished from the paraffin-embedded tissues during the years of storage. Some authors have observed that antigens had weaker staining after storage ${ }^{175 ; 176}$. One investigation showed that using the tissue microarray technique for storage, the antigenicity decreased $^{176}$. However, our tissue material was stored in paraffin-embedded blocks and we used different antigens. A difference in staining might have influenced the results in the analyses I and II, but not in III (Figure 7).

In a previous study it was demonstrated that MMP-2 expression in S-BOT was more similar to expression in benign cysts than in $\mathrm{EOC}^{177}$. There was no significant correlation between VEGF and MMP-2 expression for S-BOT in the immunhistochemistry study of Garzetti et al., while the correlation was significant between VEGF and MMP-2 among the EOC patients ${ }^{178}$. Paper 4 is to our knowledge the first one to describe an association between MMP-2 and non-invasive implant formation in $\mathrm{S}-$ BOT. The validity of this result must be confirmed by other studies. It is proposed that $\mathrm{S}_{-}$ BOT with micropapillary serous carcinoma or invasive implants might develop to well differentiated carcinomas ${ }^{19}$. However, we found that MMP were involved in non-invasive implant formation, which indicated that primary tumours with non-invasive implants might be a step along the "low-grade" pathway towards well differentiated carcinomas. 


\section{IMPLICATIONS}

\section{High-risk patients}

The ovarian consensus statement recommends prophylactic oophorectomy in women with hereditary syndromes (breast-ovarian cancer and Lynch syndrom), though it has not been scientifically proven that this approach increases survival among these patients $^{179 ; 180}$.

\section{Screening}

Currently, there are few international recommendations to introduce national screening programs in order to detect ovarian cancer at early stages. So far there is no evidence that screening in the general population would improve survival in EOC patients. Results from several large ongoing randomized trials will probably in the near future establish the impact of ovarian cancer screening on survival ${ }^{181}$.

In these trials, the basic screening tools were still pelvic examination, $\mathrm{CA}-125$ and vaginal ultrasound. The use of vaginal ultrasound might detect ovarian cysts with various grades of complexity. The more complex cysts, the more likely they were malignant. This method had low sensitivity and specificity ${ }^{181}$. In the last decades many new tumour markers and imaging techniques were tried out in order to detect ovarian cancer at earlier stages $^{182}$. However, many countries have screening programs among high risk women ${ }^{183 ; 184}$. The efficacy of such programs seems poor because the majority of cancers are still detected in advanced stages ${ }^{180}$. New technologies now exist that are required for the application of serum proteomics to cancer screening. Thus, there is a basis for optimism that novel approaches to cancer detection and screening will emerge soon ${ }^{182}$.

\section{Symptoms}

The general practitioner and gynaecologist must consider EOC diagnosis when women present with diffuse symptoms in the lower abdomen thus making earlier diagnosis possible. The general practioner and gynaecologist should ask about symptoms that are related to EOC on routine consultation ${ }^{185-187}$. If EOC is suspected, CA-125, vaginal ultrasound, pelvic examination, and CT scan should be performed. The primary physician might contribute to earlier diagnosis and treatment.

\section{Risk of malignancy index (RMI)}

In the clinical practice there is a need for techniques to discriminate benign from malignant ovarian tumours. The malignant tumours should be referred to specialized oncology centers $(\mathrm{TH})$ for treatment, while women with benign tumours can be treated at local hospitals $(\mathrm{NTH})$. Jacobs et al. developed the RMI based on clinical findings, 
ultrasonography, serum CA-125, and menopausal status (Appendix 12.1) ${ }^{188}$. Several studies have confirmed the efficiency in using the index ${ }^{93 ; 189 ; 190}$, but still this model only has a sensitivity of $78 \%$ and specificity of $80 \%{ }^{191}$. In an attempt to increase the sensitivity, a prospective international multicentre study was carried out to develop a better model to distinguish between benign and malignant adnexal mass diagnosed before surgery ${ }^{191}$. Twelve variables were included in a logistic regression model: individual history of ovarian cancer, current hormonal therapy, patient age, maximum tumour diameter, the presence of pain during the examination, the presence of ascites, the presence of blood flow within a solid papillary projection, the presence of a purely solid tumour, maximal diameter of the solid component, irregular internal cyst walls, the presence of acoustic shadows, and the colour score. This model accomplished a sensitivity of $93 \%$ and specificity of $76 \%$, and it is now prospectively evaluated.

\section{Centralization}

The present thesis has strongly contributed to the policy makers' decision to centralize ovarian cancer surgery in Norway. Paper 2 has together with other studies given evidence to the benefit of specialization in gynaecological oncology ${ }^{10 ; 72 ; 90 ; 192}$. The findings in the present papers also contributed to debate in the national press ${ }^{193}$.

The surgeons' skills were shown to be an important factor to improve EOC patients' survival. Patients operated by physicians that had operated more than ten advanced EOC patients per year had better survival (Figure 11).

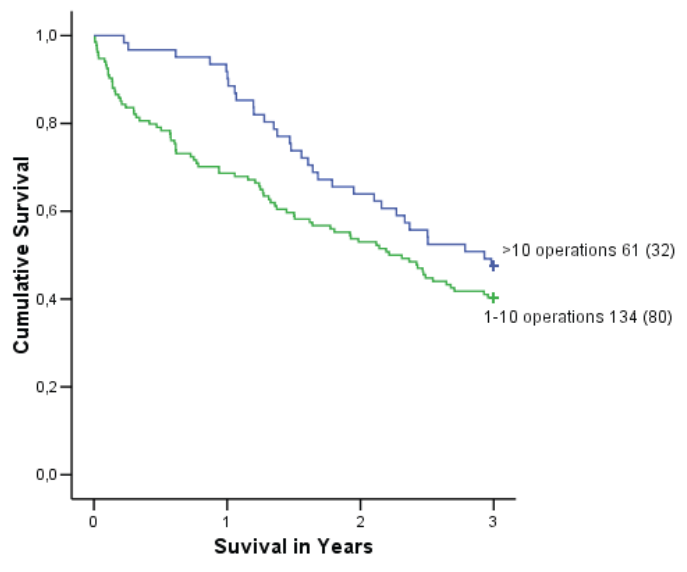

Figure 11. Kaplan-Meier survival curves for advanced ovarian/peritoneal/tubal cancer (EOC) by number of operations per operating physicians performing initial surgery. Log- 
rank test, $P=0.1$. Group with $>10$ operations, number of patients treated 61 , (32 patients are dead at end of follow-up). Group with 1-10 operations, number of patients treated 134 (80 patients are dead at end of follow-up)

One of the most important factors leading to improved survival was the physicians' ability to optimally debulk the patients. The goal of the operating physicians must be to systematically remove all visible tumours in the abdominal cavity (Figure 12).

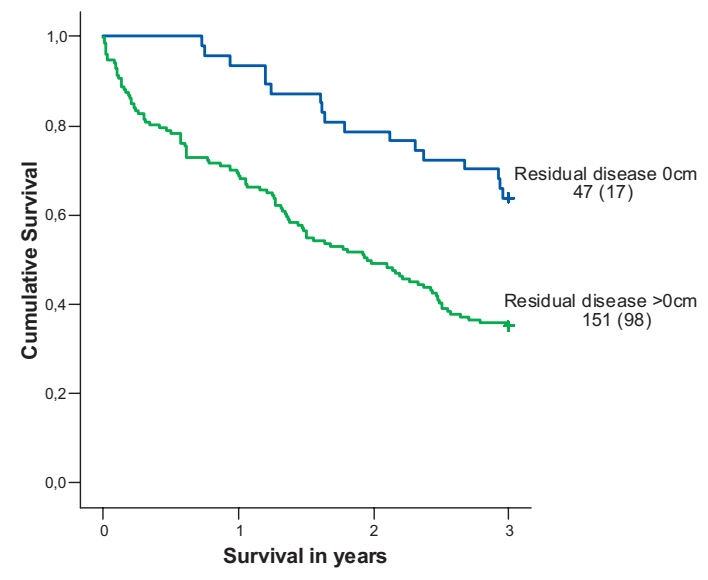

Figure 12. Kaplan-Meier plots. Three years survival of epithelial ovarian/peritoneal/tubal cancer (EOC) stage IIIC with primary diagnosis 2002 according to residual tumour more or equal to $0 \mathrm{~cm}$ in Norway, $n=198$. Date of last observation January 1 2006. Log Rank Test, $P=0.0003$. Data from OVANOR registry

One manner to achieve this goal is to make a systematic description of pre- and post-operativ tumour volume and localization in the surgical reports. The suggested scheme (Appendix 12.5) might contribute to make this goal possible. It is important to describe the number and size of remaining tumour lesions in order to quantify the amount of total residual disease. In colorectal cancer a peritoneal cancer index is used to estimate the likelihood of complete cytoreduction in patients with peritoneal surface malignancy ${ }^{194}$. Physicians operating EOC should remove the omentum in all cases. Also in BOT correct staging is important and implants should be biopsed. The operating physicians must remove suspected lesions from the abdominal cavity including implants, making a correct diagnosis possible. Still it is not known whether removal of these implants will contribute to improved survival ${ }^{48}$. 
Following publication of the data in the present thesis regarding advanced EOC treatment in Norway, the practice has changed. In 2005 a national concensus for centralization on ovarian cancer surgery in Norway was agreed on, however, not all NTH refer the patients to $\mathrm{TH}$ at the present time.

\section{Chemotherapy}

Patients with low performance status might wait several weeks before chemotherapy after surgery without having inferior survival. These patients need to recover after surgery in order to tolerate chemotherapy.

\section{Surveillance and multi-disciplinary care}

The present thesis demonstrates how clinical prospective population-based studies contribute to knowledge on symptoms and treatment of EOC. Clinical registries are valuable tools for surveillance of many diseases. These registries contribute to valuable knowledge in guiding clinicians and health care administrators to manage the health care in an appropriate way for a variety of patients.

The development of a multi-disciplinary approach might better the outcome for different patient groups ${ }^{148}$. This thesis demonstrates the importance of introducing the public health and epidemiological perspective into "small" specialties as gynaecological oncology ${ }^{195}$. It is reasonable to believe that large patient groups treated for similar diseases also have inferior outcome when treated in institutions lacking appropriate professional skill. The knowledge from this thesis might also be beneficial for these patient groups. 


\section{MAIN CONCLUSIONS}

The present thesis gave evidence to the positive effect centralization of surgery will have on survival for EOC patients.

\section{Paper 1}

More than one-third of EOC patients were referred to non-GYN units leading to delayed treatment. The majority of the patients had symptoms. The most common symptoms were 'abdominal pain' and 'distended abdomen'. 'Bowel irregularities' without 'rectal bleeding', especially in postmenopausal women were also common symptoms. Higher awareness of EOC symptoms might lead to earlier diagnosis and treatment, and possibly improve survival for these patients.

\section{Paper 2}

If the EOC patients were operated at $\mathrm{TH}$ or by specialists in gynaecological oncology, the short-term survival among these patients were improved. Centralization of surgery and formalized specialization in gynaecological oncology might improve survival for these patients.

\section{Paper 3}

Different SCI had no impact on short-term survival. Patients with low performance status may wait longer than six weeks before chemotherapy is given and these patients may be included in randomized phase III chemotherapy trials.

\section{Paper 4}

The interaction between S-BOT cells and peritoneum in formation of non-invasive implants may be influenced by the proteolytic activity of MMP-2. Patients with noninvasive implants had a nonsignificant inferior disease-free survival compared to patients without non-invasive implants. 


\section{FUTURE PERSPECTIVES AND RESEARCH}

At the end of 2006, more than 3000 patients with ovarian cancer were enrolled in the OVANOR registry, which makes continued research on epithelial and non-epithelial ovarian cancers on a population level possible. Clinical information on each patient is registered in detail with high data quality. The present registry will enable researchers to give answers to many questions about treatment and outcome for these patients. Patient selection in randomized trials often makes biased outcome. Studies should be performed on this data collection with five-years survival follow-up.

Surgical techniques have been introduced without randomized trials ${ }^{196}$. One approach in evaluating these new techniques is to perform population-based epidemiological studies in order to reveal possible differences in outcome between old and new treatment modalities (open surgery versus laparotomy or robotic surgery). The principle of population adjusted clinical epidemiology is now being implemented in Norway for other cancer types such as prostate and breast. The Cancer Registry is planning to build up clinical registries in collaboration with the clinicians for the other gynaecological malignancies.

Epidemiological studies based on data from non-EOC are now possible to perform. During the five-years existence of the OVANOR registry, approximately 200 non-EOC are recorded.

It is crucial for further development of the OVANOR registry that clinicians who are suppliers of data to the registry are working in close collaboration with those persons responsible for the registry. The reference group should make new guidelines for the OVANOR registry in collaboration with Cancer Registry. The reference group must approve protocols for doctoral thesis. The collaborating physicians and other health care providers should publish results from research in peer-reviewed journals.

A build-up of bio banks linked to the OVANOR registry will strongly contribute to research on ovarian cancer. Molecular genetics and proteomics are two fields that have developed toward clinical applications. Based on a complete patient population one might target the genes most common in the development of ovarian cancer, especially if the population-based register is linked to bio banks. With biological material collected from the majority of the ovarian cancer patients, it will secure that the genes analyzed are representative for the whole patient population. 
In clinical practice there is a need to develop prognostic tools to identify S-BOT patients with unfavorable prognosis (micropapillary serous carcinoma with invasive implants). These patients might benefit from more extensive surgical (oment and peritonectomy) and medical (cytotoxic regimens in combination with various noncytotoxic inhibitors) treatments given intravenously or intraperitoneally ${ }^{197}$. More immunhistochemistry studies of S-BOT with invasive implants and micropapillary architecture should be performed.

The enhanced expression of MMP-2 in the non-invasive implant group indicated that treatment of selective MMP-2 inhibitors might be one way of preventing recurrence in these patients ${ }^{126 ; 127 ; 198-200}$. The invasive implant group might be the most suitable group for this therapy. Allthough, MMP inhibitors in phase III trials in invasive cancers have not demonstrated clearly improved overall survival, these inhibitors might prove to be effective of S-BOT with implants because the genetic alterations for S-BOT differ from that of high grade carcinomas (Figure 3) ${ }^{126 ; 201}$.

The recent decision to discontinue reporting of BOT in the United States surveillance, epidemiology, and end results (SEER) program has eliminated a potentially valuable tool for identifying population-based cases in the United States ${ }^{197}$. Therefore it is important that other national registries continue to enroll BOT patients. It is difficult to set the correct histologic diagnosis of BOT, therefore it is important to educate general pathologists with special knowledge of BOT pathology. One limitation for further studies in the clinic and laboratories is the relatively low incidence of S-BOT with invasive implants. Hence, an international collaboration work in the laboratories and clinicians should be established ${ }^{197}$.

\section{New studies}

Influence of surgery chemotherapy interval (SCI) on disease-free survival

New analyses will be performed of the patient cohort $(n=371)$ in paper 3 . Time to recurrence will be used as end point (page 37).

\section{Neoadjuvant chemotherapy}

Patients stage II - IV enrolled in the OVANOR registry with primary diagnosis $2002-2005$ receiving chemotherapy and surgery will be identified. The group receiving chemotherapy before surgery will be compared to the group having surgery initially. In this population-based prospective study we will also include patients not included in the international randomized EORTC study ${ }^{120}$. 


\section{Capsule rupture during surgery}

A retrospective multi centre study from 2001 demonstrated inferior survival for EOC patients with stage I disease with capsule rupture during surgery ${ }^{202}$. We are carrying out a Norwegian study including patients $(n=260)$ with primary diagnosis between 2002 and 2004. Early stage EOC has good prognosis and recurrence might occur several years after primary treatment. Therefore, the observation time should be at least 3 to 5 years after diagnosis in order to record the majority of patients with recurrence. The outcome will be calculated as disease-free and cancer specific survival.

\section{Quality of life}

Relatively few studies have focused on quality of life measurements among EOC patients $^{203-205}$. A study will be done, where a quality of life questionnaire is sent to randomly selected patients enrolled in the OVANOR registry. Patients treated for primary and recurrent disease will be included. Patients with recurrence are facing a non-curable disease, hence quality of life is an important outcome variable during and after treatment for recurrence.

\section{Ovulation induction and the risk of ovarian cancer}

By linking the OVANOR registry to the hospital registries performing in vitro fertilization in Norway, one might give answer to the question if ovulation induction increase the risk of ovarian cancer ${ }^{206 ; 207}$. Women that have performed in vitro fertilization should be compared with a matched control group of women in the general population in order to calculate the standarized incidence ratio for developing ovarian cancer after in vitro fertilization. The OVANOR registry contains detailed information on all patients with ovarian cancer, why sub-analyses needed for such a study is possible to perform.

\section{BOT studies}

In order to further illuminate the mechanisms of cancer development to highly differentiated $\mathrm{EOC}^{18 ; 19}$, a study is planned using fresh specimen from cystadenomas, SBOT stage IA, S-BOT with non-invasive implants, S-BOT with invasive implants, highly differentiated EOC stage I and advanced stages. The specimen is collected prospectively from Rikshopitalet-Radiumhospitalet. We want to use micro array techniques for selected genes. The primary tumours, implants, and metastasis will be analyzed as a cross sectional study.

Later a follow-up study will be performed to identify prognostic factors useful for further studies. 


\section{REFERENCES}

1. Hippocrates. On the surgery. In: Adams F, ed. Works. London: University of Adelaide, 1849.

2. Bacon F. The essays or counsels civil and moral. New York: Oxford University Press, 1999:134.

3. Zhang AL, Wang SX, Lu YP, Li J, Wang CY, Ma D. [Correlation of expression of vascular endothelial growth factor and matrix matalloproteinase-2 to invasion of ovarian tumor cells in vitro]. Ai Zheng 2002;21:263-66.

4. Wu X, Li H, Kang L, Li L, Wang W, Shan B. Activated matrix metalloproteinase-2--a potential marker of prognosis for epithelial ovarian cancer. Gynecol Oncol 2002;84:126-34.

5. Sarraf Z, Anvari E, Eshraghian A et al. The comparision between presenting symptoms of ovarian cancer and other abdominal-pelvic cancers. Abstract No 0188. Int J Gynecol Cancer 2006;16:653.

6. Högberg T, Frankendal B, Björkholm E et al. "Gynekologisk onkologi". In: Ringborg U, Henriksson R, Friberg S, eds. Onkologi. Stockholm: Liber AB, 1998:428-79.

7. Beers MH, Berkow R. The Merck Manual. Rathway. NY: Merck \& CO, INC, 2005.

8. Goff BA, Mandel L, Muntz HG, Melancon CH. Ovarian carcinoma diagnosis. Cancer 2000;89:2068-75.

9. Cancer in Norway 2004 Cancer Registry of Norway 2006.

10. Bristow RE, Berek JS. Surgery for ovarian cancer: how to improve survival. Lancet 2006;367:1558-60.

11. del Carmen MG. Primary Epithelial Ovarian Cancer: Diagnosis and Management. In: Perry MC, ed. American Society of Clinical Oncology. 2006 Educational Book. Alexandria, VA, USA: American Society of Clinical Oncology, 2006:330-334.

12. Beers MH, Berkow R. Classification and staging of malignant tumours in the female pelvis. Acta Obstet Gynecol Scand 1971;50:1-7.

13. Heintz AP, Odicino F, Maisonneuve P et al. Carcinoma of the ovary. J Epidemiol Biostat 2001;6:107-38.

14. Kurman RJ, Trimble CL. The behavior of serous tumors of low malignant potential: are they ever malignant? Int J Gynecol Pathol 1993;12:120-127.

15. Seidman JD, Kurman RJ. Subclassification of serous borderline tumors of the ovary into benign and malignant types. A clinicopathologic study of 65 advanced stage cases. Am J Surg Pathol 1996;20:1331-45.

16. Berek JS. Epithelial Ovarian Cancer. In: Berek JS, Hacker NF, eds. Practical Gynecological Oncology. Baltimore: Williams \& Wilkins, 1994:327-75. 
17. Tavassoli FA, Devilee P. Tumors of the Ovaries and Peritoneum. In: Tavassoli FA, Devilee P, eds. Pathology \& Genetics Tumours of the Breast and Female Genital Organs. Lyon: IARC Press, 2003:113-202.

18. Shih I, Kurman RJ. Ovarian tumorigenesis: a proposed model based on morphological and molecular genetic analysis. Am J Pathol 2004;164:1511-18.

19. Shih I, Kurman RJ. Molecular pathogenesis of ovarian borderline tumors: new insights and old challenges. Clin Cancer Res 2005;11:7273-79.

20. Levi F, Franceschi S, La-Vecchia C, Ruzicka J, Gloor E, Randimbison L. Epidemiologic pathology of ovarian cancer from the Vaud Cancer Registry, Switzerland. Ann Oncol 1993;4:289-94.

21. Fathalla MF. Incessant ovulation--a factor in ovarian neoplasia? Lancet 1971;2:163.

22. Germani D, Belli S, Bruno C et al. Cohort mortality study of women compensated for asbestosis in Italy. Am J Ind Med 1999;36:129-34.

23. Langseth H, Johansen BV, Nesland JM, Kjaerheim K. Asbestos fibers in ovarian tissue from Norwegian pulp and paper workers. Int J Gynecol Cancer 2007;17:44-49.

24. Risch HA. Hormonal etiology of epithelial ovarian cancer, with a hypothesis concerning the role of androgens and progesterone. J Natl Cancer Inst 1998;90:1774-86.

25. Srivastava A, McKinnon W, Wood ME. Risk of breast and ovarian cancer in women with strong family histories. Oncology (Williston Park) 2001;15:889-902.

26. Riman T, Nilsson S, Persson IR. Review of epidemiological evidence for reproductive and hormonal factors in relation to the risk of epithelial ovarian malignancies. Acta Obstet Gynecol Scand 2004;83:783-95.

27. Engeland A, Tretli S, Bjorge T. Height, body mass index, and ovarian cancer: a followup of 1.1 million Norwegian women. J Natl Cancer Inst 2003;95:1244-48.

28. Wright JD, Powell MA, Mutch DG et al. Relationship of ovarian neoplasms and body mass index. J Reprod Med 2005;50:595-602.

29. Baker JA, Odunuga OO, Rodabaugh KJ, Reid ME, Menezes RJ, Moysich KB. Active and passive smoking and risk of ovarian cancer. Int J Gynecol Cancer 2006;16 Suppl 1:211-18.

30. Schildkraut JM, Moorman PG, Halabi S, Calingaert B, Marks JR, Berchuck A. Analgesic drug use and risk of ovarian cancer. Epidemiology 2006;17:104-7.

31. Cottreau CM, Ness RB, Kriska AM. Physical activity and reduced risk of ovarian cancer. Obstet Gynecol 2000;96:609-14.

32. Weiderpass E, Margolis KL, Sandin S et al. Prospective study of physical activity in different periods of life and the risk of ovarian cancer. Int J Cancer 2006. 
33. Zubrod CG, Schneidermann M, Frei E et al. Appraisal of methods for the study of chemotherapy of cancer in man: comparative therapeutic trial of nitrogen mustard and triethylene thiophosphoramide. J Chron Dis 1960;11:7-33.

34. Kaern J, Trope CG, Kristensen GB, Pettersen EO. Flow cytometric DNA ploidy and Sphase heterogeneity in advanced ovarian carcinoma. Cancer 1994;73:1870-1877.

35. Torng PL, Mao TL, Chan WY, Huang SC, Lin CT. Prognostic significance of stromal metalloproteinase-2 in ovarian adenocarcinoma and its relation to carcinoma progression. Gynecol Oncol 2004;92:559-67.

36. Skirnisdottir I, Seidal T, Sorbe B. A new prognostic model comprising p53, EGFR, and tumor grade in early stage epithelial ovarian carcinoma and avoiding the problem of inaccurate surgical staging. Int J Gynecol Cancer 2004;14:259-70.

37. Nishida N, Yano H, Komai K, Nishida T, Kamura T, Kojiro M. Vascular endothelial growth factor $\mathrm{C}$ and vascular endothelial growth factor receptor 2 are related closely to the prognosis of patients with ovarian carcinoma. Cancer 2004;101:1364-74.

38. Marth C, Fiegl H, Zeimet AG et al. Interferon-gamma expression is an independent prognostic factor in ovarian cancer. Am J Obstet Gynecol 2004;191:1598-605.

39. Kaern J, Aghmesheh M, Nesland JM et al. Prognostic factors in ovarian carcinoma stage III patients. Can biomarkers improve the prediction of short- and long-term survivors? Int J Gynecol Cancer 2005;15:1014-22.

40. Matei D, Graeber TG, Baldwin RL, Karlan BY, Rao J, Chang DD. Gene expression in epithelial ovarian carcinoma. Oncogene 2002;21:6289-98.

41. Schwartz DR, Kardia SL, Shedden KA et al. Gene expression in ovarian cancer reflects both morphology and biological behavior, distinguishing clear cell from other poorprognosis ovarian carcinomas. Cancer Res 2002;62:4722-29.

42. Berchuck A, Iversen ES, Lancaster JM et al. Prediction of optimal versus suboptimal cytoreduction of advanced-stage serous ovarian cancer with the use of microarrays. Am J Obstet Gynecol 2004;190:910-925.

43. De Smet F, Pochet NL, Engelen K et al. Predicting the clinical behavior of ovarian cancer from gene expression profiles. Int J Gynecol Cancer 2006;16 Suppl 1:14751.

44. Klausner RD. The fabric of cancer cell biology-Weaving together the strands. Cancer Cell 2002;1:3-10.

45. Foulds L. The Experimental Study of Tumor Progression. London: Academic Press, 1954.

46. Hanahan D, Weinberg RA. The hallmarks of cancer. Cell 2000;100:57-70.

47. Boyd J. Specific keynote: hereditary ovarian cancer: what we know. Gynecol Oncol 2003;88:S8-10. 
48. Zanetta G, Rota S, Chiari S, Bonazzi C, Bratina G, Mangioni C. Behavior of borderline tumors with particular interest to persistence, recurrence, and progression to invasive carcinoma: a prospective study. J Clin Oncol 2001;19:2658-64.

49. Gu J, Roth LM, Younger $\mathrm{C}$ et al. Molecular evidence for the independent origin of extra-ovarian papillary serous tumors of low malignant potential. $J$ Natl Cancer Inst 2001;93:1147-52.

50. Ortiz BH, Ailawadi M, Colitti C et al. Second primary or recurrence? Comparative patterns of p53 and K-ras mutations suggest that serous borderline ovarian tumors and subsequent serous carcinomas are unrelated tumors. Cancer Res 2001;61:726467.

51. Gross J, Lapier CM. Collagenolytic activity in amphibian tissues: a tissue culture assay. Proc Natl Acad Sci U S A 1962;48:1014-22.

52. Birkedal-Hansen H, Moore WG, Bodden MK et al. Matrix metalloproteinases: a review. Crit Rev Oral Biol Med 1993;4:197-250.

53. Nagase H, Visse R, Murphy G. Structure and function of matrix metalloproteinases and TIMPs. Cardiovasc Res 2006;69:562-73.

54. Allan JA, Docherty AJ, Barker PJ, Huskisson NS, Reynolds JJ, Murphy G. Binding of gelatinases A and B to type-I collagen and other matrix components. Biochem J 1995;309 ( Pt 1):299-306.

55. Murphy G, Crabbe T. Gelatinases A and B. Methods Enzymol 1995;248:470-484.

56. Strongin AY, Collier I, Bannikov G, Marmer BL, Grant GA, Goldberg GI. Mechanism of cell surface activation of 72-kDa type IV collagenase. Isolation of the activated form of the membrane metalloprotease. J Biol Chem 1995;270:5331-38.

57. Bjorklund M, Koivunen E. Gelatinase-mediated migration and invasion of cancer cells. Biochim Biophys Acta 2005;1755:37-69.

58. Woessner JF, Jr. Matrix metalloproteinases and their inhibitors in connective tissue remodeling. FASEB J 1991;5:2145-54.

59. Lehti K, Lohi J, Valtanen H, Keski-Oja J. Proteolytic processing of membrane-type-1 matrix metalloproteinase is associated with gelatinase A activation at the cell surface. Biochem J 1998;334 ( Pt 2):345-53.

60. Goodman MT, Correa CN, Tung KH et al. Stage at diagnosis of ovarian cancer in the United States, 1992-1997. Cancer 2003;97:2648-59.

61. Pecorelli S, Jones III HW, Ngan HY, Bender HG, Benedet JL. Staging classifications and the clinical practice guidelines of gynecologic cancers by the FIGO Committee on Gynecologic Oncology. Elsevier, 2000:1-107.

62. Maggioni A, Benedetti PP, Dell'Anna $T$ et al. Randomised study of systematic lymphadenectomy in patients with epithelial ovarian cancer macroscopically confined to the pelvis. Br J Cancer 2006;95:699-704. 
63. Morice P, Joulie F, Camatte S et al. Lymph node involvement in epithelial ovarian cancer: analysis of 276 pelvic and paraaortic lymphadenectomies and surgical implications. J Am Coll Surg 2003;197:198-205.

64. Zanetta G, Chiari S, Rota S et al. Conservative surgery for stage I ovarian carcinoma in women of childbearing age. Br J Obstet Gynaecol 1997;104:1030-1035.

65. Meigs JV. Tumors of the female pelvic organs. New York: Macmillan, 1934.

66. Aure JC, Hoeg K, Kolstad P. Clinical and histologic studies of ovarian carcinoma. Long-term follow-up of 990 cases. Obstet Gynecol 1971;37:1-9.

67. Griffiths CT. Surgical resection of tumor bulk in the primary treatment of ovarian carcinoma. Natl Cancer Inst Monogr 1975;42:101-4.

68. Baker TR, Piver MS, Hempling RE. Long term survival by cytoreductive surgery to less than $1 \mathrm{~cm}$, induction weekly cisplatin and monthly cisplatin, doxorubicin, and cyclophosphamide therapy in advanced ovarian adenocarcinoma. Cancer 1994;74:656-63.

69. Warwick J, Kehoe S, Earl H, Luesley D, Redman C, Chan KK. Long-term follow-up of patients with advanced ovarian cancer treated in randomised clinical trials. $\mathrm{Br} \mathrm{J}$ Cancer 1995;72:1513-17.

70. Curtin JP, Malik R, Venkatraman ES, Barakat RR, Hoskins WJ. Stage IV ovarian cancer: impact of surgical debulking. Gynecol Oncol 1997;64:9-12.

71. Le T, Krepart GV, Lotocki RJ, Heywood MS. Does debulking surgery improve survival in biologically aggressive ovarian carcinoma? Gynecol Oncol 1997;67:208-14.

72. Junor EJ, Hole DJ, McNulty L, Mason M, Young J. Specialist gynaecologists and survival outcome in ovarian cancer: a Scottish national study of 1866 patients. $\mathrm{Br} J$ Obstet Gynaecol 1999;106:1130-1136.

73. Bristow RE, Tomacruz RS, Armstrong DK, Trimble EL, Montz FJ. Survival effect of maximal cytoreductive surgery for advanced ovarian carcinoma during the platinum era: a meta-analysis. J Clin Oncol 2002;20:1248-59.

74. Silver DF. Full-thickness diaphragmatic resection with simple and secure closure to accomplish complete cytoreductive surgery for patients with ovarian cancer. Gynecol Oncol 2004;95:384-87.

75. Todo Y, Sakuragi N, Oikawa M et al. Cytoreductive surgery combined with organ resection for advanced ovarian carcinoma. Int J Clin Oncol 2003;8:90-96.

76. Bilgin T, Ozerkan K, Ozan H. Splenectomy in cytoreductive surgery for advanced ovarian cancer. Arch Gynecol Obstet 2005;271:329-31.

77. Horowitz NS, Duska LR. Advances in the surgical management of ovarian cancer. $J$ Reprod Med 2005;50:454-66. 
78. Gungor T, Sahin I, Demeril C, Terzioglu H, Mollamahmutoglu L. Impact of splenectomy in surgical management of ovarian cancer. Abstract No 0278. Int J Gynecol Cancer 2006;16:679.

79. Crawford SC, Vasey PA, Paul J, Hay A, Davis JA, Kaye SB. Does aggressive surgery only benefit patients with less advanced ovarian cancer? Results from an international comparison within the SCOTROC-1 Trial. $J$ Clin Oncol 2005;23:8802-11.

80. Eisenkop SM, Spirtos NM, Lin WC. Splenectomy in the context of primary cytoreductive operations for advanced epithelial ovarian cancer. Gynecol Oncol 2005.

81. Zanaboni F, Heintz AP, Trimbos JB, van Lindert AC, Aalders JG, Neijt JP. The role of cytoreduction in ovarian cancer. Eur J Gynaecol Oncol 1988;9:149-52.

82. Kehoe S. Primary debulking surgery in advanced ovarian carcinoma. Br J Obstet Gynaecol 1996;103:291-93.

83. Högberg T. Primary surgery in ovarian cancer: current opinions. Ann Med 1995;27:95100.

84. Eisenkop SM, Spirtos NM, Friedman RL, Lin WC, Pisani AL, Perticucci S. Relative influences of tumor volume before surgery and the cytoreductive outcome on survival for patients with advanced ovarian cancer: a prospective study. Gynecol Oncol 2003;90:390-396.

85. Schrag D, Earle C, Xu F et al. Associations between hospital and surgeon procedure volumes and patient outcomes after ovarian cancer resection. J Natl Cancer Inst 2006;98:163-71.

86. Eisenkop SM, Spirtos NM, Montag TW, Nalick RH, Wang HJ. The impact of subspecialty training on the management of advanced ovarian cancer. Gynecol Oncol 1992;47:203-9.

87. Kehoe S, Powell J, Wilson S, Woodman C. The influence of the operating surgeon's specialisation on patient survival in ovarian carcinoma. Br J Cancer 1994;70:101417.

88. Junor EJ, Hole DJ, Gillis CR. Management of ovarian cancer: referral to a multidisciplinary team matters. Br J Cancer 1994;70:363-70.

89. Woodman C, Baghdady A, Collins S, Clyma JA. What changes in the organisation of cancer services will improve the outcome for women with ovarian cancer? [see comments]. Br J Obstet Gynaecol 1997;104:135-39.

90. Engelen MJ, Kos HE, Willemse PH et al. Surgery by consultant gynecologic oncologists improves survival in patients with ovarian carcinoma. Cancer 2006;106:589-98.

91. Earle CC, Schrag D, Neville BA et al. Effect of surgeon specialty on processes of care and outcomes for ovarian cancer patients. J Natl Cancer Inst 2006;98:172-80. 
92. Kumpulainen S, Grenman S, Kyyronen P, Pukkala E, Sankila R. Evidence of benefit from centralised treatment of ovarian cancer: a nationwide population-based survival analysis in Finland. Int J Cancer 2002;102:541-44.

93. Tingulstad S, Skjeldestad FE, Hagen B. The effect of centralization of primary surgery on survival in ovarian cancer patients. Obstet Gynecol 2003;102:499-505.

94. Ghaemmaghami E, Hassanzadeh M, Fallahi A. Centralization of ovarain cancer surgery: Do patients benefit? Abstract No 0144. Int J Gynecol Cancer 2006;16:641.

95. Munstedt K, von Georgi R, Misselwitz B, Zygmunt M, Stillger R, Kunzel W. Centralizing surgery for gynecologic oncology--a strategy assuring better quality treatment? Gynecol Oncol 2003;89:4-8.

96. Chemotherapy of advanced ovarian adenocarcinoma: a randomized comparison of combination versus sequential therapy using chlorambucil and cisplatin Gynecol Oncol 1986;23:1-13.

97. Randomised comparison of cisplatin with cyclophosphamide/cisplatin and with cyclophosphamide/doxorubicin/cisplatin in advanced ovarian cancer. Gruppo Interegionale Cooperativo Oncologico Ginecologia Lancet 1987;2:353-59.

98. Long-term results of a randomized trial comparing cisplatin with cisplatin and cyclophosphamide with cisplatin, cyclophosphamide, and adriamycin in advanced ovarian cancer. GICOG (Gruppo Interregionale Cooperativo Oncologico Ginecologia), Italy Gynecol Oncol 1992;45:115-17.

99. McGuire WP, Hoskins WJ, Brady MF et al. Assessment of dose-intensive therapy in suboptimally debulked ovarian cancer: a Gynecologic Oncology Group study. $J$ Clin Oncol 1995;13:1589-99.

100. Tropé C, Andersson H, Bjorkholm E et al. Doxorubicin-melphalan with and without cisplatin in advanced ovarian cancer--ten-year survival results from a prospective randomized study by the Swedish Cooperative Ovarian Cancer Study Group. Acta Oncol 1996;35 Suppl 8:109-18.

101. Bolis G, Favalli G, Danese S et al. Weekly cisplatin given for 2 months versus cisplatin plus cyclophosphamide given for 5 months after cytoreductive surgery for advanced ovarian cancer. J Clin Oncol 1997;15:1938-44.

102. Jakobsen A, Bertelsen K, Andersen JE et al. Dose-effect study of carboplatin in ovarian cancer: a Danish Ovarian Cancer Group study. J Clin Oncol 1997;15:19398.

103. Piccart MJ, Bertelsen K, James K et al. Randomized intergroup trial of cisplatinpaclitaxel versus cisplatin- cyclophosphamide in women with advanced epithelial ovarian cancer: three-year results. J Natl Cancer Inst 2000;92:699-708.

104. du Bois A, Luck HJ, Meier W et al. Carboplatin/paclitaxel versus cisplatin/paclitaxel as first-line chemotherapy in advanced ovarian cancer: an interim analysis of a randomized phase III trial of the Arbeitsgemeinschaft Gynakologische Onkologie Ovarian Cancer Study Group. Semin Oncol 1997;24:S15. 
105. Neijt JP, Engelholm SA, Tuxen MK et al. Exploratory phase III study of paclitaxel and cisplatin versus paclitaxel and carboplatin in advanced ovarian cancer. $J$ Clin Oncol 2000;18:3084-92.

106. Bookman MA, Greer BE, Ozols RF. Optimal therapy of advanced ovarian cancer: carboplatin and paclitaxel vs. cisplatin and paclitaxel (GOG 158) and an update on GOG0 182-ICON5. Int J Gynecol Cancer 2003;13:735-40.

107. Oksefjell H, Sandstad B, Tropé C. Improved survival for ovarian cancer patients stage IIIC treated at the Norwegian Radium hospital between 1984 and 2001. Submitted. Eur J Gynaecol Oncol 2007.

108. Ketcham AS, Kinsey DL, Wexler H, Mantel N. The development of spontaneous metastases after the removal of a "primary" tumor. II. Standardization protocol of 5 animal tumors. Cancer 1961;14:875-82.

109. Fisher B, Gunduz N, Saffer EA. Influence of the interval between primary tumor removal and chemotherapy on kinetics and growth of metastases. Cancer Res 1983;43:1488-92.

110. Sorbe B. Prognostic importance of the time interval from surgery to chemotherapy in treatment of ovarian carcinoma. Int J Gynecol Cancer 2004;14:788-93.

111. Gadducci A, Sartori E, Landoni F et al. Relationship between time interval from primary surgery to the start of taxane- plus platinum-based chemotherapy and clinical outcome of patients with advanced epithelial ovarian cancer: results of a multicenter retrospective Italian study. J Clin Oncol 2005;23:751-58.

112. Armstrong DK, Bundy B, Wenzel L et al. Intraperitoneal cisplatin and paclitaxel in ovarian cancer. $N$ Engl J Med 2006;354:34-43.

113. Markman M, Bundy BN, Alberts DS et al. Phase III trial of standard-dose intravenous cisplatin plus paclitaxel versus moderately high-dose carboplatin followed by intravenous paclitaxel and intraperitoneal cisplatin in small-volume stage III ovarian carcinoma: an intergroup study of the Gynecologic Oncology Group, Southwestern Oncology Group, and Eastern Cooperative Oncology Group. J Clin Oncol 2001;19:1001-7.

114. Alberts DS, Liu PY, Hannigan EV et al. Intraperitoneal cisplatin plus intravenous cyclophosphamide versus intravenous cisplatin plus intravenous cyclophosphamide for stage III ovarian cancer. N Engl J Med 1996;335:1950-1955.

115. De Bree E, Rosing H, Beijnen JH et al. Pharmacokinetic study of docetaxel in intraoperative hyperthermic i.p. chemotherapy for ovarian cancer. Anticancer Drugs 2003;14:103-10.

116. Yoshida Y, Sasaki H, Kurokawa T et al. Efficacy of intraperitoneal continuous hyperthermic chemotherapy as consolidation therapy in patients with advanced epithelial ovarian cancer: a long-term follow-up. Oncol Rep 2005;13:121-25. 
117. De Bree E, Rosing H, Michalakis J et al. Intraperitoneal chemotherapy with taxanes for ovarian cancer with peritoneal dissemination. Eur J Surg Oncol 2006;32:66670 .

118. Sugarbaker PH, Clarke L. The approval process for hyperthermic intraoperative intraperitoneal chemotherapy. Eur J Surg Oncol 2006;32:637-43.

119. Sugarbaker PH, Stuart OA, Yoo D. Strategies for management of the peritoneal surface component of cancer: cytoreductive surgery plus perioperative intraperitoneal chemotherapy. J Oncol Pharm Pract 2005;11:111-19.

120. Vergote, I. Randomized phase III study comparing upfront debulking surgery vs neoadjuvant chemotherpy in patients with stage IIIC or IV epithelial ovarian carcinoma. EORTC 55971-NCIC CTG OV13 Protocol. 1999.

121. Vergote I, De W, I, Tjalma W, Van Gramberen M, Decloedt J, van Dam P. Neoadjuvant chemotherapy or primary debulking surgery in advanced ovarian carcinoma: a retrospective analysis of 285 patients. Gynecol Oncol 1998;71:43136.

122. Lawton FG, Redman CW, Luesley DM, Chan KK, Blackledge G. Neoadjuvant (cytoreductive) chemotherapy combined with intervention debulking surgery in advanced, unresected epithelial ovarian cancer. Obstet Gynecol 1989;73:61-65.

123. Rose PG, Nerenstone S, Brady MF et al. Secondary surgical cytoreduction for advanced ovarian carcinoma. $N$ Engl J Med 2004;351:2489-97.

124. Dupont J, Aghajanian C, Sabbatini P, Spriggs DR. New agents for the treatment of ovarian cancer: the next generation. Int J Gynecol Cancer 2005;15 Suppl 3:252-57.

125. Penson RT, Cannistra SA, Seiden MV, Krasner CN, Matulonis UA. Phase II study of Carboplatin, Paclitaxel, and Bevacizumab as first-line chemotherapy and consolidation for advanced Müllerian tumors. Abstract 5020. J Clin Oncol 2006;24:260s.

126. Hirte H, Vergote IB, Jeffrey J, Grimshaw R. A phase III randomized trial of BAY 129566 (tanomastat) as maintenence therapy in patients with advanced ovarien cancer responsive to primary surgery and paclitaxel/platinum chemotherapy: A National Cancer Institute of Canada Clinical Trials Group Study. Gynecol Oncol 2006.

127. Molina JR, Reid JM, Erlichman C et al. A phase I and pharmacokinetic study of the selective, non-peptidic inhibitor of matrix metalloproteinase BAY 12-9566 in combination with etoposide and carboplatin. Anticancer Drugs 2005;16:997-1002.

128. Bidus MA, Webb JC, Seidman JD, Rose GS, Boice CR, Elkas JC. Sustained response to bevacizumab in refractory well-differentiated ovarian neoplasms. Gynecol Oncol 2006;102:5-7.

129. Cohn DE, Valmadre S, Resnick KE, Eaton LA, Copeland LJ, Fowler JM. Bevacizumab and weekly taxane chemotherapy demonstrates activity in refractory ovarian cancer. Gynecol Oncol 2006;102:134-39. 
130. Monk BJ, Han E, Josephs-Cowan CA, Pugmire G, Burger RA. Salvage bevacizumab (rhuMAB VEGF)-based therapy after multiple prior cytotoxic regimens in advanced refractory epithelial ovarian cancer. Gynecol Oncol 2006;102:140-144.

131. Hurwitz H, Fehrenbacher L, Novotny W et al. Bevacizumab plus irinotecan, fluorouracil, and leucovorin for metastatic colorectal cancer. $N$ Engl J Med 2004;350:2335-42.

132. Sandler AB, Gray R, Brahmer J. Randomized phase II/III trial pf paclitaxel (P) plus carboplatin (C) with or without bevacizumab (NSC\#704865) in patients with advanced non-squamous non-small cell lung cancer (NSCLC): An Eastern Cooporative Oncology Group (ECOG) Trial-E4599. ASCO Annual Meeting Proceeding, (June 1 Supplement). J Clin Oncol 2006;23.

133. Hepp R, Baeza MR, Olfos P, Suarez E. Adjuvant whole abdominal radiotherapy in epithelial cancer of the ovary. Int J Radiat Oncol Biol Phys 2002;53:360-365.

134. Smith RP, Gillies McKenna W. The basic of radiation therapy. In: Abeloff MD, Armitage JO, Niederhuber JE, Kastan MB, McKenna WG, eds. Clinical Ocology. Philadelphia: Elsevier. Churchill Livingstone, 2004:537-78.

135. Kaldor JM, Day NE, Kittelmann B et al. Bladder tumours following chemotherapy and radiotherapy for ovarian cancer: a case-control study. Int J Cancer 1995;63:16.

136. Murray EM, Werner D, Greeff EA, Taylor DA. Postradiation sarcomas: 20 cases and a literature review. Int J Radiat Oncol Biol Phys 1999;45:951-61.

137. Therasse P, Arbuck SG, Eisenhauer EA et al. New guidelines to evaluate the response to treatment in solid tumors. European Organization for Research and Treatment of Cancer, National Cancer Institute of the United States, National Cancer Institute of Canada. J Natl Cancer Inst 2000;92:205-16.

138. McDowel.E. Three cases of extirpation of diseased ovaria. Eclectic Repertory and Analytic Review 7, 242. 1817.

139. Munstedt K, Franke FE. Role of primary surgery in advanced ovarian cancer. World $J$ Surg Oncol 2004;2:32.

140. Eisenkop SM, Spirtos NM. Division of pedicles by stapling during cytoreductive surgery for ovarian cancer. Gynecol Oncol 2005;97:852-57.

141. Fagotti A, Fanfani F, Ludovisi M et al. Role of laparoscopy to assess the chance of optimal cytoreductive surgery in advanced ovarian cancer: a pilot study. Gynecol Oncol 2005;96:729-35.

142. Giede KC, Kieser K, Dodge J, Rosen B. Who should operate on patients with ovarian cancer? An evidence-based review. Gynecol Oncol 2005;99:447-61.

143. Senecoff SD, Mellen HS. Clinical remission of adenocarcinoma of the ovary induced by triethylene thiophosphoramide. Report of a case. Bull Sinai Hosp Detroit 1962;10:98-100. 
144. Bookman MA. GOGO182-ICON5: 5-arm phase III ranomized trial of paclitaxel (P) and carboplatin (C) vs combinations with gemcitabine (G), PEG-liposomal doxorubicine (D), or topotecan (T) in patients (pts) with advanced-stage epithelial ovarian (EOC) or primary peritoneal (PPC) carcinoma. Abstract 5002. J Clin Oncol 2006;24[18S]:256s.

145. Andersen, G. Clinical trials NSGO. http: \|www.nsgo.org】. 2006.

146. Charlton BG, Taylor PR, Proctor SJ. The PACE (population-adjusted clinical epidemiology) strategy: a new approach to multi-centred clinical research. QJM 1997;90:147-51.

147. Rothman KJ, Greenland S. Modern Epidemiology. Philadelphia, USA: Lippincott Williams \& Wilkins, 1998:1-738.

148. Confidential Enquiry into Maternal and Child Health. http://www.cemach.org.uk/links.htm. 2006.

149. Regulations on the collection and processing of personal health data in the Cancer Registry. 2001.

150. Paulsen T, Kjaerheim K, Kaern J, Norstein J, Onsrud M. [Examination, treatment and follow-up of ovarian cancer in Norway]. Tidsskr Nor Laegeforen 2001;121:2696700 .

151. Statistics Norway. http://www.ssb.nolenglish/2006.

152. International Statistical Classification of Diseases. Injuries, and Causes of Death. http://www.who.int/classifications/icd/en/. Tenth Revision[Geneva]. 2006. WHO.

153. SNOMED. http://www.snomed.org/. 2006.

154. Serov S, Scully R, Sobin L. Histological typing of ovarian tumors. International histologic classification of tumors, vol 9. Geneva: WHO, 1973:37-38.

155. Harvei S, Tretli S, Langmark F. Quality of prostate cancer data in the cancer registry of Norway. Eur J Cancer 1996;32A:104-10.

156. Helseth A, Langmark F, Mork SJ. Neoplasms of the central nervous system in Norway. I. Quality control of the registration in the Norwegian Cancer Registry. APMIS 1988;96:1002-8.

157. Tingulstad S, Halvorsen T, Norstein J, Hagen B, Skjeldestad FE. Completeness and accuracy of registration of ovarian cancer in the cancer registry of Norway. Int $J$ Cancer 2002;98:907-11.

158. dos Santos Silva I. Introduction to survival analysis. Cancer Epidemilogy: Principles and Methods. Lyon, France: World Health Organization. International Agency for Research on Cancer, 1999:291-92. 
159. Zhu K, McKnight B, Stergachis A, Daling JR, Levine RS. Comparison of self-report data and medical records data: results from a case-control study on prostate cancer. Int J Epidemiol 1999;28:409-17.

160. Vine MF, Ness RB, Calingaert B, Schildkraut JM, Berchuck A. Types and duration of symptoms prior to diagnosis of invasive or borderline ovarian tumor. Gynecol Oncol 2001;83:466-71.

161. Lataifeh IM, Marsden DE, Robertson G, Gebski V, Hacker N. Presenting symptoms of epithelial ovarian cancer. Abstract No 0284. Int J Gynecol Cancer 2006;16:681.

162. Nilsson SE, Johansson B, Berg S, Karlsson D, McClearn GE. A comparison of diagnosis capture from medical records, self-reports, and drug registrations: a study in individuals 80 years and older. Aging Clin Exp Res 2002;14:178-84.

163. Skinner KM, Miller DR, Lincoln E, Lee A, Kazis LE. Concordance between respondent self-reports and medical records for chronic conditions: experience from the Veterans Health Study. J Ambul Care Manage 2005;28:102-10.

164. Rufford BD, Hussain U, Jacobs IJ, Menon U. Symptoms in women with ovarian cancer compared to those referred for targeted ovarian screening. Abstract No 0193. Int J Gynecol Cancer 2006;16:655.

165. Kumpulainen S, Kuoppala T, Leminen A et al. Surgical treatment of ovarian cancer in different hospital categories - A prospective nation-wide study in Finland. Eur $J$ Cancer 2006;42:388-95.

166. Cliby WA, Aletti GD, Wilson TO, Podratz KC. Is it justified to classify patients to Stage IIIC epithelial ovarian cancer based on nodal involvement only? Gynecol Oncol 2006.

167. Hafner GH, Herrera L, Petrelli NJ. Morbidity and mortality after pelvic exenteration for colorectal adenocarcinoma. Ann Surg 1992;215:63-67.

168. Smedh K, Olsson L, Johansson H, Aberg C, Andersson M. Reduction of postoperative morbidity and mortality in patients with rectal cancer following the introduction of a colorectal unit. Br J Surg 2001;88:273-77.

169. Venesmaa P, Ylikorkala O. Morbidity and mortality associated with primary and repeat operations for ovarian cancer. Obstet Gynecol 1992;79:168-72.

170. Charlson ME, Pompei P, Ales KL, MacKenzie CR. A new method of classifying prognostic comorbidity in longitudinal studies: development and validation. $J$ Chronic Dis 1987;40:373-83.

171. Aletti GD, Dowdy SC, Gostout BS et al. Aggressive surgical effort and improved survival in advanced-stage ovarian cancer. Obstet Gynecol 2006;107:77-85.

172. Chi DS, Franklin CC, Levine DA et al. Improved optimal cytoreduction rates for stages IIIC and IV epithelial ovarian, fallopian tube, and primary peritoneal cancer: a change in surgical approach. Gynecol Oncol 2004;94:650-654. 
173. Makar A, Kisic J, Tropé C. Controversies in surgical treatment of advanced ovarian cancer (Stage III-IV). Eur J Gynaecol Oncol 2000;5:449-60.

174. Sherman ME, Mink PJ, Curtis R et al. Survival among women with borderline ovarian tumors and ovarian carcinoma: a population-based analysis. Cancer 2004; 100:1045-52.

175. Risio M, De Rosa G, Sarotto I et al. HER2 testing in gastric cancer: molecular morphology and storage time-related changes in archival samples. Int $J$ Oncol 2003;23:1381-87.

176. Fergenbaum JH, Garcia-Closas M, Hewitt SM, Lissowska J, Sakoda LC, Sherman ME. Loss of antigenicity in stored sections of breast cancer tissue microarrays. Cancer Epidemiol Biomarkers Prev 2004;13:667-72.

177. Määttä M, Santala M, Soini Y, Talvensaari-Mattila A, Turpeenniemi-Hujanen T. Matrix metalloproteinases 2 and 9 and their tissue inhibitors in low malignant potential ovarian tumors. Tumour Biol 2004;25:188-92.

178. Garzetti GG, Ciavattini A, Lucarini G et al. Expression of vascular endothelial growth factor related to 72-kilodalton metalloproteinase immunostaining in patients with serous ovarian tumors. Cancer 1999;85:2219-25.

179. Thigpen JT. Ovaries and Fallopian Tubes. In: Abeloff MD, Armitage JO, Niederhuber JE, Kastan MB, McKenna WG, eds. Clinical Oncology. Philadelphia: Elsevier. Churchill Livingstone, 2004:2311-45.

180. Gaarenstroom KN, van der HB, Tollenaar RA et al. Efficacy of screening women at high risk of hereditary ovarian cancer: results of an 11-year cohort study. Int $J$ Gynecol Cancer 2006;16 Suppl 1:54-59.

181. Menon U, Jacobs IJ. Ovarian cancer screening in the general population: current status. Int J Gynecol Cancer 2001;11 Suppl 1:3-6.

182. Jacobs IJ, Menon U. Progress and challenges in screening for early detection of ovarian cancer. Mol Cell Proteomics 2004;3:355-66.

183. Dorum A, Hovig E, Trope C, Inganas M, Moller P. Three per cent of Norwegian ovarian cancers are caused by BRCA1 $1675 \mathrm{delA}$ or $1135 \mathrm{insA}$. Eur J Cancer 1999;35:779-81.

184. Dorum A, Heimdal K, Lovslett K et al. Prospectively detected cancer in familial breast/ovarian cancer screening. Acta Obstet Gynecol Scand 1999;78:906-11.

185. Goff BA, Mandel LS, Melancon CH, Muntz HG. Frequency of symptoms of ovarian cancer in women presenting to primary care clinics. JAMA 2004;291:2705-12.

186. Hughes KS, Roche C, Campbell CT et al. Prevalence of family history of breast and ovarian cancer in a single primary care practice using a self-administered questionnaire. Breast $J$ 2003;9:19-25. 
187. Lamberts H, Oskam SK, Okkes IM. [The clinical relationship between symptoms and the final diagnosis in general practice, determined by means of posterior probabilities calculated on the basis of the Transition Project]. Ned Tijdschr Geneeskd 2005; 149:2566-72.

188. Jacobs I, Oram D, Fairbanks J, Turner J, Frost C, Grudzinskas JG. A risk of malignancy index incorporating CA 125 , ultrasound and menopausal status for the accurate preoperative diagnosis of ovarian cancer. $\mathrm{Br} J$ Obstet Gynaecol 1990;97:922-29.

189. Davies AP, Jacobs I, Woolas R, Fish A, Oram D. The adnexal mass: benign or malignant? Evaluation of a risk of malignancy index. Br J Obstet Gynaecol 1993;100:927-31.

190. Manjunath AP PSKVR. Comparison of Three Risk of Malignancy Indices in Evaluation of Pelvic Masses. Gynecol Oncol 2001;81:225-29.

191. Timmerman D, Testa AC, Bourne $\mathrm{T}$ et al. Logistic regression model to distinguish between the benign and malignant adnexal mass before surgery: a multicenter study by the International Ovarian Tumor Analysis Group. J Clin Oncol 2005;23:8794801.

192. Carney ME, Lancaster JM, Ford C, Tsodikov A, Wiggins CL. A population-based study of patterns of care for ovarian cancer: who is seen by a gynecologic oncologist and who is not? Gynecol Oncol 2002;84:36-42.

193. Skogstøm, L. [More patients are dying of cancer at local hospitals]. Aftenposten , 252-2005.

194. da Silva RG, Sugarbaker PH. Analysis of prognostic factors in seventy patients having a complete cytoreduction plus perioperative intraperitoneal chemotherapy for carcinomatosis from colorectal cancer. J Am Coll Surg 2006;203:878-86.

195. Jenum AK, Ødegaard AK. [All physicians should have basic competence in community medicine]. Tidsskr Nor Laegeforen 2005;125:619-20.

196. Draaisma WA, Ruurda JP, Scheffer RC et al. Randomized clinical trial of standard laparoscopic versus robot-assisted laparoscopic Nissen fundoplication for gastrooesophageal reflux disease. Br J Surg 2006;93:1351-59.

197. Sherman ME, Berman J, Birrer MJ et al. Current challenges and opportunities for research on borderline ovarian tumors. Hum Pathol 2004;35:961-70.

198. Eisenhauer EA, Gore M, Neijt JP. Ovarian cancer: should we be managing patients with good and bad prognostic factors in the same manner? Ann Oncol 1999;10 Suppl 1:9-15.

199. Rosano L, Spinella F, Salani D et al. Therapeutic targeting of the endothelin a receptor in human ovarian carcinoma. Cancer Res 2003;63:2447-53. 
200. Wu M, Xu G, Xi L et al. Down-regulation of MT1-MMP expression suppresses tumor cell invasion in metastatic human SW626 ovarian cancer cells. Oncol Rep 2006;15:501-5.

201. Zucker S, Cao J, Chen WT. Critical appraisal of the use of matrix metalloproteinase inhibitors in cancer treatment. Oncogene 2000;19:6642-50.

202. Vergote I, De Brabanter J, Fyles A et al. Prognostic importance of degree of differentiation and cyst rupture in stage I invasive epithelial ovarian carcinoma. Lancet 2001;357:176-82.

203. Liavaag AH, Dorum A, Fossa SD, Tropé C, Dahl AA. A controlled sudy of somatic morbidity, mental distress, fatigue, and quality of life in short and long-term epithelial ovarian cancer survivors. Abstract No 0599. Int J Gynecol Cancer 2006; $16: 768$.

204. Wilailak S, Lohacharoenvanich N, Luengsukcharoen S et al. Quality of life of gynecological cancer patients after treatment. Abstract No 0065. Int J Gynecol Cancer 2006;16:618.

205. Wenzel L, Huang HQ, Monk BJ, Rose PG, Cella D. Quality-of-life comparisons in a randomized trial of interval secondary cytoreduction in advanced ovarian carcinoma: a Gynecologic Oncology Group study. J Clin Oncol 2005;23:5605-12.

206. Venn A, Healy D, McLachlan R. Cancer risks associated with the diagnosis of infertility. Best Pract Res Clin Obstet Gynaecol 2003;17:343-67.

207. Dor J, Lerner-Geva L, Rabinovici J et al. Cancer incidence in a cohort of infertile women who underwent in vitro fertilization. Fertil Steril 2002;77:324-27. 